\title{
Reliable Supply Chain Network Design
}

\begin{abstract}
Risk management in supply chains has been receiving increased attention in the past few years. In this paper, we present formulations for the strategic supply chain network design problem with dual objectives, which usually conflict with each other: minimizing cost and maximizing reliability. Quantifying the total reliability of a network design is not as straightforward as total cost calculation. We use reliability indices and develop analytical formulations that model the impact of upstream supply chain on individual entities' reliability to quantify the total reliability of a network. The resulting multi-objective non-linear model is solved using a novel hybrid algorithm that utilizes a genetic algorithm for network design and linear programming for network flow optimization. We demonstrate the application of our approach through illustrative examples in establishing tradeoffs between cost and reliability in network design and present managerial implications.
\end{abstract}

Keywords: supply chain risk, reliability, multi-objective optimization, heuristics, network design

\section{INTRODUCTION}


Managing and controlling risk is an important aspect of effective supply chain management (Sodhi and Tang, 2012; Sodhi et al., 2012). In order to control and mitigate negative effects caused by a variety of risks, a significant amount of work in the area of supply chain risk management has been undertaken in both academia and practitioner circles. The commonly identified and studied risk types include supply risk (Harland et al., 2003; Chopra and Sodhi, 2004; Wu et al., 2006; Bogataj and Bogataj, 2007; Tang and Tomlin, 2008; Vakharia and Yenipazarli, 2009; Kumar et al., 2010; Tummala and Schoenherr, 2011), demand risk (Christopher and Peck, 2004; Blackhurst et al., 2008; Manuj and Mentzer, 2008; Wagner and Bode, 2008), manufacturing risk (Tang, 2006; Olson and Wu, 2010; Lin and Zhou, 2011), financial risk (Carvinato, 2004; Tsai, 2008; Liu and Nagurney, 2011), macro risk (e.g., environmental risk, natural disasters, terrorist attacks, political and social risk) (Jüttner et al., 2003; Trkman and McCormack, 2009; Ravindran et al., 2010), and information risk (Tang and Musa, 2011). Moreover, increased global competition and the lingering effects of the 2008 global financial crisis have placed tremendous pressure on firms to lower their operating costs. However, mitigating risks and lowering costs are goals that often conflict. The complexities of today's supply chain networks, coupled with these conflicting goals, demand the use of new analytical approaches to effectively manage the tradeoffs that arise.

In a typical network design problem, there exists an underlying network, consisting of suppliers, plants, distribution centers (DC), and transportation infrastructure and modes linking those entities. In addition, there are also potential new locations to choose from. In this context, the decisions that need to be made include: Which of the existing and new locations should be used? Which customers should be served from which DCs? Which suppliers should supply which plants? While making these decisions, there needs to be a method for quantifying 
reliability of a network design so that different options can be compared based on total reliability and total cost. In addressing these important questions and related issues, we propose to assign a reliability index, based on multi-criteria modeling, to each entity and activity and simultaneously consider cost and reliability in identifying the best set of designs that achieve near Pareto optimality. In order to accomplish this, we develop analytical formulations based on multiobjective optimization methods and use heuristics to solve these formulations. Since we are using a heuristic for solving our models, we are unable to measure how close our solutions are to the Pareto front. Because of this we refer to our solution set as near Pareto solutions.

While reliability is a complex construct, the primary advantage of utilizing a single value to capture the reliability of an entity in a network is its practicality and the ease with which it can be incorporated into the decision-making process. Tomlin (2006) uses a single reliability measure for characterizing two different suppliers' reliabilities in managing supply chain disruptions. Parlar and Wang (1993) also apply a single parameter in a random yields model to capture the difference in reliability between two suppliers. On the other hand, the main disadvantage of using a single value is the loss of information due to aggregation. Chopra et al. (2007) point out the importance of decoupling different characteristics of one risk from another type of risk. They characterize two different types of risks, recurrent risk and disruption risk, using separate and independent parameters.

Overall, we consider the usage of a single value as a reasonable way to capture the reliability of an entity since there are several techniques that can aggregate multiple criteria into one meaningful index without loss of valuable information. Khorramshahgol et al. (1998) integrate multiple perceptions into an overall synthesis by using analytic hierarchy process (AHP). Kull 
and Talluri (2008) and Yoon et al. (2014) also apply the same approach to aggregate multiple risk factors in capturing suppliers’ reliability.

To optimize our formulations, it is essential to develop a meaningful way of computing total reliability of a network, similar to the approach that is utilized to calculate the total cost. If we assume that each entity in a supply chain is independent of other entities, one can simply consider the summation of the reliability indices of a network design to obtain the total reliability, similar to a total cost calculation. In reality, however, the entities in a supply chain are very much interrelated. In fact, in alignment with the well-known phrase "A chain is only as strong as its weakest link", it can be stated that an entity in a network is only as reliable as its upstream supply chain.

The novelty of this paper lies in this attempt to analytically model the impact of upstream supply chain reliability while quantifying total reliability. For this, we separate the reliability index of an entity into two parts: inherent reliability (due to several factors, which we elaborate in more detail in the Appendix C) and reliability due to its upstream chain. We propose a compounding mechanism to capture the impact of upstream reliability on the entities in the downstream. Furthermore, we develop optimization methods to identify the best set of designs by simultaneously considering cost minimization and reliability maximization in establishing related tradeoffs and achieving near Pareto optimality.

\section{LITERATURE REVIEW}

Supply chain risk management is a relatively new area of study, which is continuing to expand with the volume of published research articles growing exponentially on a yearly basis. In the past decade, six review articles in supply chain risk management have been published (Tang, 2006; Narasimhan and Talluri, 2009; Rao and Goldsby, 2009; Tang and Musa, 2011; Colicchia 
and Strozzi, 2012; Sodhi et al., 2012). While most businesses used to ignore the risk of catastrophic events, a growing interest has been observed in the $21^{\text {st }}$ century in focusing on such risks (e.g., Martha and Vratimos, 2002; Berger et al., 2004; Chopra and Sodhi, 2004; SimchiLevi et al., 2004; Tang, 2006; Wagner and Bode, 2008; Knemeyer et al., 2009; Meena et al., 2011).

In the early stages of the supply chain risk management research, risk has been addressed mainly in the context of internal factors such as manufacturing processes, which are subject to demand and lead-time uncertainties (e.g., Zipkin, 2000). Naylor et al. (1999) show that the combination of agile and lean manufacturing is able to reduce the risk of being out of stock under conditions of demand uncertainty. Gupta and Maranas (2003) propose an optimization model for manufacturing and distribution timing decisions in order to achieve cost reduction under demand uncertainty. In addition to manufacturing processes, vast literature considers safety stocks and warehouses between manufacturers and retailers as the means to reduce the effect of demand and lead-time uncertainties (Schwarz and Weng, 1989; Axsäter, 1993; Federgruen, 1993; Inderfurth, 1994; Diks et al., 1996; Van Houtum et al., 1996; Schwarz and Weng, 2000).

As academic interest began to grow in supply chain risk management, external providers have also been considered as a major source of supply chain vulnerability (Klibi et al., 2010). Davis (1993) argues that suppliers' performance plays a prominent role in the efficiency of a supply chain. In the same vein, an industrial survey conducted by Protiviti and American Production \& Inventory Control Society (APICS) shows that 66\% of supply chain managers consider supply interruption as one of their most significant concerns among all the supply chain related risks (O'Keeffe, 2006). Supplier's unreliability is captured by two main approaches: (i) 
supply disruption model and (ii) random-yield model. In the supply disruption model (e.g., Parlar and Perry, 1995; Parlar, 1997; Snyder et al., 2010), a supplier’s status is either “up” or “down”, where "up" means that the orders are fulfilled in full and on time, and "down" means no order can be fulfilled. Ruiz-Torres and Mahmoodi (2007) extend the model of Berger et al. (2004) to determine the optimal number of suppliers in the presence of supplier failure risks, and considered the partial costs resulting from having some of the suppliers down. Li et al. (2010) investigate the sourcing strategies of the retailer and the pricing game played between suppliers in a single-retailer and two-supplier supply chain in the presence of supply disruption. Gümüş et al. (2012) model a supply chain consisting of a single buyer and two suppliers, both of which compete for the buyer's orders and face risk of supply disruption. Hendricks and Singhal (2003; 2005a; 2005b) examined several hundred supply chain "glitches" reported in the Wall Street Journal and the Dow Jones News Service in the 1990s. They show that disruptions, even minor, lead to significant declines in sales growth, stock returns, and shareholder wealth of companies. Moreover, these effects tend to linger for at least two years after the disruption.

In a random-yield model, it is assumed that the supply level is a random function of the input level (e.g., Yano and Lee, 1995; Gurnani et al., 2000; Grosfeld-Nir and Gerchak, 2004; He and Zhang, 2008). Graves (1987) provides a survey of many analytical models for determining production and inventory policies under this assumption with emphasis on random demand. Yu et al. (2009) evaluate the impact of supply disruption risks on the choice between single and dual sourcing methods in a two-stage supply chain with a non-stationary and price-sensitive demand. Schmitt et al. (2010) develop a closed-form approximate solution by focusing on a single stochastic period of demand, which can help firms proactively and cost effectively protect against supply disruption risk. Schmitt (2011) formulates a linear programming model for a 
multi-echelon system to evaluate multiple strategies for minimizing expected lost sales if a supply disruption occurs. Shi et al. (2011) develop a multi-stage stochastic programming model to minimize the risk exposure of procurement decisions measured as conditional value-at-risk, while considering stochastic demand and the price volatility of the spot market.

When it comes to transportation issues, contemporary supply chain studies treat transportation as a strategically interrelated but physically independent entity in the supply chain (i.e., 3PL provider), which implies that transportation issues also can be considered as an external factor of supply chain vulnerability (Yoon et al., 2014). In the same vein, Tang (2006) points out the importance of transportation issues in supply chain risk mitigation. Reliable and robust transportation network design is another important topic studied in this context (e.g., Liu and Tipper, 2001; Zabarabkin et al., 2001). Chen et al. (2007) propose a stochastic bi-level optimization model for minimizing the total travel time budget required to satisfy the predefined reliability constraint. Andreas et al. (2008) consider $h$-path network routing problem to minimize transportation cost subject to a specified reliability requirement such that at least one path retains reliability beyond minimum level. Desai and Sen (2010) apply a branch-and-bound algorithm for designing a reliable transportation network by assuming that there exists an arbitrary set of risk mitigation resources in each arc with its constraints.

A few studies consider the design of supply chain networks under different aspects of uncertainty. Vidal and Goetschalckx (1997) and Goetschalckx (2000) survey the strategic supply chain design issues. Literature on reliability and robustness of supply chain networks is even scarce although these aspects can simultaneously deal with different elements of uncertainties mentioned earlier. Vidal and Goetschalckx (2000) present an approach that includes suppliers' reliability as a criterion of supply chain design. Sheffi (2001) introduces dual supply 
arrangements in a strategic supply chain design and provides an illustrative analytical formulation for the design. Snyder and Daskin (2005) present a facility location model that performs well under both normal operating conditions and when distribution centers in the network fail. Tomlin (2006) analytically presents a generalized supply chain design model by focusing on supplier selection and order allocation with consideration of disruptions under two different suppliers setting: one is perfectly reliable but expensive and the second being unreliable but cheaper. Chopra et al. (2007) utilize the same dual supplier setting (reliable and unreliable) and provide an analytical design model while considering not only disruption risks but also recurrent risks that cause random yield. Qi et al. (2010) consider a supply chain design problem that determines the locations of retailers and assignments of customers to retailers under supply disruption risk. Georgiadis et al. (2011) construct a mixed integer linear programming model for supply chain network design under uncertain transient demand variations. Qiang and Nagurney (2012) develop a linear programming model for the design and evaluation of distinct supply chain networks under capacity and demand disruptions.

Our study focuses on supply chain network design while explicitly considering transportation risk in addition to other risks. Among the many previous studies on supply chain risk management, our work is closest to that of Neureuther and Kenyon (2008) and Bundschuh et al. (2006) and our research can be viewed, at some level, as a hybrid of the two. Neureuther and Kenyon (2008) define the risk index of an entity as the ratio of time to resume to time until the collapse of the supply chain. More specifically, they calculate the risk consequence $\alpha \in(0,1)$ by $\frac{\delta_{\text {replace }}}{\delta_{\text {collapse }}}$, where $\delta_{\text {replace }}$ can be defined as the time required to restore a particular node to full functionality after a disruption and $\delta_{\text {collapse }}$ as the time a given service can fail to be delivered before the supply chain suffers the loss of a critical mass of its market share. Given this, they 
calculate the total risk of a given supply chain network, without considering the design problem. Our paper also assigns indices to the entities and uses those indices to calculate the total reliability of the network but there are three main differences. First, we define the reliability indices based on multiple factors so that they can be more general. Second, we capture the impact of upstream supply chain on the reliability of the entities in the downstream through a compounding mechanism. Third, we not only calculate the total reliability of a given network design, we also identify the best network design based on a given parameter set including cost, reliability, and weights.

Bundschuh et al. (2006) consider the strategic network design problem and propose several models. They consider the probabilities for reliability calculations and impose constraints for robustness (i.e., redundant suppliers, contingency inventory, etc.) to investigate the tradeoff between reliability, robustness, and cost. They present the reliability-contingency model to leverage all three distinct characteristics to create an optimal strategy. Their model recognizes the potential for supply failures and establishes an action plan to counteract the negative effects. Our approach differs from their work in the following ways. First, our model explicitly treats reliability maximization as a separate objective and models the problem as a multi-objective problem, whereas Bundschuh et al. (2006) model reliability as a constraint. Second, the reliability of the entities are assumed to be independent in Bundschuh et al. (2006), whereas we incorporate the inherent dependence of downstream entities' reliability on the upstream chain. Third, the reliability of a node in Bundschuh et al. (2006) is defined as the probability of normal functioning of a node, whereas a failure is defined as the inability to ship any quantity of materials. We instead treat the reliability index as a more comprehensive value that takes into account not only the probability of failure but also a set of other relevant factors. 
As noted earlier, we take a more comprehensive view of reliability when compared to the above approaches and, more importantly, develop a new approach to analytically model the impact of upstream reliability in a supply chain while quantifying total reliability by utilizing a compounding mechanism. In addition to addressing the near Pareto optimality decisions in network design, we identify possible risk mitigation strategies implied by the solutions obtained in our analysis.

\section{MODEL FORMULATION}

We initially define the parameters and indices utilized in the formulation followed by the decision variables, objective functions, and constraints.

\section{Parameters and Indices}

$$
\begin{aligned}
& A \quad=\text { set of arcs } \\
& N=\text { set of nodes } \\
& S \quad=\text { set of raw material suppliers } \\
& D=\text { set of final customer nodes } \\
& I(j)=\text { set of nodes adjacent to node } \mathrm{j} \text { with an incoming arc }[i, j] \in A \\
& O(j)=\text { set of nodes adjacent to node } \mathrm{j} \text { with an outgoing arc }[j, k] \in A \\
& c_{i}=\text { variable cost per unit offered by node } i \\
& f_{i}=\text { fixed cost for node } i \\
& b_{i j}=\text { variable cost per unit offered by arc }[i, j] \\
& g_{i j}=\text { fixed cost for arc }[i, j] \\
& h_{i}=\text { holding cost per unit at node } i \\
& s_{i}=\text { shortage cost per unit at node } i \in D \\
& K_{i}=\text { capacity of node } i \in N \backslash D \\
& D_{i}=\text { demand of node } i \in D \\
& D S=\text { demand satisfaction level, } 0 \leq D S \leq 1 \\
& M_{i} \quad=\text { minimum ordering quantity offered by node } i \in N \backslash D \\
& M \quad=\text { a sufficiently large number, e.g. total demand of customers }
\end{aligned}
$$


$r_{i}=$ per-unit reliability index of node $i, 0 \leq r_{i} \leq 1$

$r_{i j}=$ per-unit reliability index of $\operatorname{arc}[i, j], 0 \leq r_{i j} \leq 1$

$R_{i}=$ per-unit cumulative reliability index of node $i$

$R_{i j}=$ per-unit cumulative reliability index of arc $[i, j]$

$w_{i}=$ weight of node $i$ in compounding calculations, $0 \leq w_{i} \leq 1$

$w_{i j}=$ weight of arc $[i, j]$ in compounding calculations, $0 \leq w_{i j} \leq 1$

\section{Decision variables}

$X_{i j} \quad=$ integer ordering quantity from node $i$ to node $j$

$\forall[i, j] \in A$

$S_{i} \quad=$ shortage quantity at node $i$

$\forall i \in D$

$Y_{i}=\left\{\begin{array}{l}1 \text { if node } i \text { is selected } \\ 0 \text { otherwise }\end{array}\right.$

$\forall i \in N \backslash D$

$Z_{i j}=\left\{\begin{array}{l}1 \text { if arc }[i, j] \text { is selected } \\ 0 \text { otherwise }\end{array}\right.$

$\forall[i, j] \in A$

\section{Objective Functions}

Minimize Total Cost:

$$
\begin{array}{r}
\min \sum_{i \in N \backslash D}\left(f_{i} Y_{i}+c_{i} \sum_{j \in N} X_{i j}\right)+\sum_{[i, j] \in A}\left(g_{i j} Z_{i j}+b_{i j} X_{i j}\right) \\
+\sum_{j \in N \backslash(D \cup S)} h_{j}\left(\sum_{i \in I(j)} X_{i j}-\sum_{k \in O(j)} X_{j k}\right)+\sum_{i \in D} s_{i} S_{i}
\end{array}
$$

Maximize Total Reliability:

$$
\max \sum_{i \in N \backslash D} R_{i} \sum_{j \in N} X_{i j}+\sum_{[i, j] \in A} R_{i j} X_{i j}
$$

(Obj 1) is the sum of fixed and variable costs for nodes and arcs, inventory holding costs and shortage costs. Inventory holding costs may be incurred because of minimum order quantities required by suppliers. Shortage costs may be incurred since full demand satisfaction is not required. (Obj 2) is the sum of node and arc reliability, both weighted with the order quantity. 
To be more specific, in the consideration of (Obj 2) the following details are important. In this model, total reliability is calculated by summing the reliability indices of selected nodes and arcs, each multiplied by the total amount of flow that goes through the corresponding nodes and arcs. This is because of the observation that, without weighing the reliability indices with the flow amount, two nodes (or arcs) that have the same reliability index would have the same impact on the total reliability even when one may have much more flow-through (order quantity) than the other. In reality, if we want the supply chain design to be reliable, we would want to ship the most, if not all, of the orders through reliable nodes and arcs. (Obj 2) achieves this by weighting the reliability summations with total order quantities flowing through the nodes and arcs.

\section{Constraints}

$$
\begin{array}{ll}
\sum_{j \in O(i)} X_{i j} \leq K_{i} Y_{i} & \forall i \in O \backslash D \\
\sum_{i \in I(j)} X_{i j}-\sum_{k \in O(j)} X_{j k} \geq 0 & \forall j \in N \backslash(D \cup S) \\
\sum_{i \in I(j)} X_{i j} \leq D_{j} & \forall j \in D \\
X_{i j} \leq M Z_{i j} & \forall[i, j] \in A \\
Z_{i j} \leq X_{i j} & \forall[i, j] \in A \\
\sum_{j \in O(i)} X_{i j} \geq M_{i} Y_{i} & \forall i \in N \backslash D \\
\sum_{i \in I(j)} X_{i j} \geq D_{j}-S_{j} & \forall j \in D \\
\frac{S_{i} \leq 1-D S}{D_{i}} & \forall i \in D \\
R_{i j}= &
\end{array}
$$




$$
\begin{aligned}
& R_{i}=\left\{\begin{array}{cl}
w_{i}^{\prime} r_{i}+w_{k i}^{\prime} \min _{(k, i) \in A: k \in I(i)}\left(Z_{k i} R_{k i}+M\left(1-Z_{k i}\right)\right. & \text { (MIN) } \\
w_{i}^{\prime} r_{i}+w_{k i}^{\prime} \max _{(k, i) \in A: k \in I(i)}\left(Z_{k i} R_{k i}\right) & \text { (MAX) } \\
w_{i}^{\prime} r_{i}+w_{k i}^{\prime} \frac{\sum_{(k, i) \in A: k \in I(i)} R_{k i} Z_{k i}}{\sum_{(k, i) \in A: k \in I(i)} Z_{k i}} & \text { (AVERAGE) }
\end{array}\right. \\
& w_{i j}+w_{i}=1 \\
& w_{i}^{\prime}+w_{k i}^{\prime}=1
\end{aligned}
$$

Constraint (1) ensures that flows through outgoing arcs from a certain node $i$ can occur only if node $i$ is selected and the total flow cannot exceed the capacity of node $i$, (2) ensures that outgoing flow of a node does not exceed the incoming flow to that node, (3) ensures that incoming flow to a customer node does not exceed the demand of that customer node, (4) considers that an arc is selected if a flow goes through that arc, (5) enforces the use of arc $[i, j]$, once it is selected. This constraint is redundant for optimization with only (Obj 1) but required for heuristics with (Obj 2). Constraint (6) forces minimum order requirement for each node. Constraints (7) and (8) are the shortage constraints for demand nodes. Constraint (7) ensures that the flow into a customer satisfies the demand minus the shortage, whereas (8) limits the maximum allowed shortage as a percentage of the demand. Constraint (9) defines the compounding mechanism used to calculate the cumulative reliability of an $\operatorname{arc}[i, j]$ as a weighted sum of its inherent reliability index and the cumulative reliability index of the node $i$ that is incident to the arc. Similarly, Constraints (10.1-10.3) define the three different compounding mechanisms used individually to calculate the cumulative reliability index of node $i$ as a weighted sum of its inherent reliability index and a function of the cumulative reliability indices of the arcs that are inputs into node $i$. Finally, Constraints (11) and (12) define the weights used in equations (9) and (10), respectively.

Total Supply Chain Reliability Calculations 
Given the inherent reliability indices of nodes and arcs in a network, quantifying the total reliability can be performed in a similar fashion as calculating the total flow cost of that network by summing up the products of reliability indices of entities with the flow through those entities. We refer to this as the "non-compounding" approach.

However, this type of a calculation is trivial and it disregards the impact of upstream supply chain on downstream individual entities' reliability. As mentioned earlier, to overcome this, we separate the reliability index of an entity into two parts: inherent reliability and reliability due to its upstream chain. We propose three different compounding mechanisms to capture the impact of upstream processes on the entities in the downstream. The first function (10.1) represents the "pessimistic" view on the impact of upstream supply chain since the least reliable arc (and its subsequent upstream) is used to calculate the cumulative reliability index of node $i$ with the “minimum” function.

An opposite "maximum" function is used in (10.2), which represents the "optimistic" view since the most reliable arc (and its subsequent upstream) is used to calculate the cumulative reliability index of node $i$.

The last function used in (10.3) is the "middle ground" between the two extremes, where the "average" of all the reliability indices of incoming arcs is used to calculate the cumulative reliability index of node $i$. The three compounding mechanisms are illustrated through Figure 1, where node $i$ 's inherent reliability index is 6 and $\operatorname{arcs}[x, i]$ and $[y, i]$ 's cumulative reliability indices are 2 and 8 , respectively.

Insert Figure 1 Here

With no compounding, node $i$ 's index would remain 6. For illustration purposes, let's assume that the weights of the upstream reliability and the inherent reliability are the same (have equal 
weights of 0.5). With "min" compounding, $R_{i}=0.5 \times 6+0.5 \times \min (2,8)=4$. Thus, it is evident that working with an unreliable entity in the upstream significantly reduces the reliability for node $i$ from 6 to 4 .

With "max" compounding, $R_{i}=0.5 \times 6+0.5 \times \max (2,8)=7$. Thus, we see that working with a reliable entity in the upstream increases the reliability for node $i$ from 6 to 7.

With “average” compounding, $R_{i}=0.5 \times 6+0.5 \times \frac{2+8}{2}=5.5$. In this last case, the impact of the upstream is as not as drastic as the two previous cases.

In our model, we differentiate the weights used for the inherent reliability and that of the upstream chain since the focal firm and its upstream chain may have different level of impact on the overall reliability of the firm's supply chain. To base the weights on industry data, we look at the value add of firms to their products with respect to the value add of their upstream chain and use this as a proxy for the relative impact of the firm and its upstream supply chain on its products. Based on the U.S Census Bureau ${ }^{1}$, the ratio of total cost of material (including freight) to total value of shipment is about $60 \%(\$ 3,240,477,063 / \$ 5,498,599,159)$. Thus we can attribute $60 \%$ of the economic value of the products of the firms to their upstream chain and the remaining $40 \%$ can be attributed to the firm itself. Thus, we use a weight of 0.4 for the inherent reliability and a weight of 0.6 for the upstream chain of the node.

\section{SOLUTION METHODOLOGY}

As noted earlier, the problem we are considering is a multi-objective optimization problem with two conflicting objective functions. We try to balance the two objectives using a min-max strategy to obtain near Pareto optimal solutions. The min-max strategy compares relative

1 http://factfinder2.census.gov/faces/tableservices/jsf/pages/productview.xhtml?pid=ASM_2011_31GS101\&prodTy pe=table 
deviations from the separately attainable optimum solutions by solving the optimization problems for each objective separately. We use the following master formulation to perform this:

$$
\min Q
$$

s.t.

$$
\begin{gathered}
\frac{w_{c}(C S-B C)}{B C} \leq Q \\
-\frac{w_{r}(R K-B R)}{B R} \leq Q
\end{gathered}
$$

And Constraint (1) through (12)

, where

$Q \quad=$ a variable to balance the two objectives

$w_{c}=$ weight for the cost objective

$w_{r}=$ weight for the reliability objective

$C S=$ the cost objective function (equation Obj 1)

$R K=$ the reliability objective function (equation Obj 2)

$B C=$ value of the cost achieved when Obj 1 is optimized in isolation

$B R=$ value of the reliability achieved when Obj 2 is optimized in isolation

As stated earlier, the min-max strategy requires the separately attainable optimum solutions ( $B C$ and $B R$ ) by solving the optimization problems for each objective independently. To accomplish this, we solve the model with (Obj 1) and constraints (1-8) as an integer linear program (note that constraints (9-12) have no effect in this optimization and so they can be disregarded). Unfortunately, the same strategy cannot be used with (Obj 2) since constraints (10.1-10.3) are non-linear. Because of this, we develop a Genetic Algorithm (GA) to optimize the model comprised of (Obj 2) and constraints (1) - (12). Since constraints (14) and (15) in the min-max formulation are also non-linear, we again revert to the GA approach to solve this problem. GA has been successfully used for non-linear optimization problems in the literature. These include the works of Yokoto et al. (1996) on solving system reliability problems, Lin et 
al.(1999) on mechanical design, Costa and Oliveira (2001) on chemical engineering problems, Deb (2001) on goal programming and engineering design problems. In their book on GA, Sivanandam and Deepa (2008)state that genetic algorithms (and other evolutionary computation techniques) have drawn attention due to the fact that GA do not have much mathematical requirements. Because of that, they are applied to non-linear problems in the fields of medicine, engineering, network design and routing, etc.GA is an adaptive heuristic search method based on population genetics. The GA consists of a population of solutions that evolve over a number of generations and are subject to genetic operators at each generation. Our heuristic is a hybrid of GA and Linear Programming (LP). In our heuristic, the network structure is handled by the GA and the flow quantity assignments are determined by optimizing an LP. To accomplish this, the algorithm first generates a set of feasible random network solutions by randomly fixing the binary decision variables. Once the binary variables are fixed, the rest of the problem becomes a LP, which is solved using a commercial optimization software. Once the solutions are obtained, crossover and mutation operators are applied to obtain new solutions.

Most of the developmental work of GA theory was performed using a binary-coded GA (Holland (1975), Goldberg (1989, 1991), and, historically is the most widely used representation. In a binary coding, each solution is a vector comprised of zeroes and ones. We employ a binary coding as it fits well for the network design problems. In this coding, nodes of the network are assigned 0 or 1 . In addition, all possible arcs between the node echelons (i.e., between suppliers and plants or between plants and DCs) are also assigned 0 or 1 . The following example demonstrates the representation of a solution: 
Example 1: Given three suppliers (1, 2, 3), four plants (4, 5, 6, 7), five DCs $(8,9,10,11,12)$ and five customers (A, B, C, D, E), we present a sample solution, as shown in Figure 2, and its representation.

Insert Figure 2 Here

\begin{tabular}{|c|c|c|c|c|c|c|c|c|c|c|c|c|}
\hline Node & 1 & 2 & 3 & 4 & 5 & 6 & 7 & 8 & 9 & 10 & 11 & 12 \\
\hline Coding & 0 & 1 & 1 & 0 & 0 & 1 & 1 & 1 & 1 & 1 & 0 & 0 \\
\hline
\end{tabular}

\begin{tabular}{|c|c|c|c|c|c|c|c|c|c|c|c|c|}
\hline Arc & 13 & 14 & 15 & 16 & 17 & 18 & 19 & 20 & 21 & 22 & 23 & 24 \\
\hline $\begin{array}{c}\text { Connected } \\
\text { nodes }\end{array}$ & 1,4 & 1,5 & 1,6 & 1,7 & 2,4 & 2,5 & 2,6 & 2,7 & 3,4 & 3,5 & 3,6 & 3,7 \\
\hline Coding & 0 & 0 & 0 & 0 & 0 & 0 & 1 & 0 & 0 & 0 & 0 & 1 \\
\hline
\end{tabular}

\begin{tabular}{|c|c|c|c|c|c|c|c|c|c|c|c|c|c|c|c|c|c|c|c|c|}
\hline Arc & 25 & 26 & 27 & 28 & 29 & 30 & 31 & 32 & 33 & 34 & 35 & 36 & 37 & 38 & 39 & 40 & 41 & 42 & 43 & 44 \\
\hline Connected & 4, & 4, & 4, & 4, & 4, & 5, & 5, & 5, & 5, & 5, & 6, & 6, & 6, & 6, & 6, & 7, & 7, & 7, & 7, & 7, \\
nodes & 8 & 9 & 10 & 11 & 12 & 8 & 9 & 10 & 11 & 12 & 8 & 9 & 10 & 11 & 12 & 8 & 9 & 10 & 11 & 12 \\
\hline Selection & 0 & 0 & 0 & 0 & 0 & 0 & 0 & 0 & 0 & 0 & 1 & 0 & 1 & 0 & 0 & 0 & 1 & 0 & 0 & 0 \\
\hline
\end{tabular}

\subsection{Initial Population of Solutions}

The initial set of solutions is formed randomly with a corrective mechanism to create meaningful solutions. First the nodes are randomly selected and then the arcs between the selected nodes are randomly chosen. Finally, nodes that do not have any incoming arcs are removed from the solution. All arcs that were outgoing from such nodes are also eliminated. Similarly, nodes that do not have any outgoing arcs are also removed from the solution, along with the arcs that were incoming to such nodes.

\subsection{Genetic Operators}

\subsubsection{Crossover}

A crossover operator is used to generate a new solution from two randomly selected parent solutions using a normal distribution. A solution that has a higher objective function value is more likely to be selected as a parent solution. 
A single crossover point is selected, using a uniform distribution, for the part of the solution corresponding to the nodes, which is comprised of three segments: supplier nodes, plant nodes, and DC nodes. If the crossover point corresponds to suppliers, all other plant and DC nodes and arcs between the nodes are transferred based on the crossover performed at the supplier nodes segment using a simple procedure to ensure feasibility in the offspring. The basic idea is that if the offspring inherits supplier genes from its parents, it will also inherit the arcs starting from the supplier nodes, the plant nodes that the arcs are ending at, and the arcs starting from the plant nodes. To illustrate this procedure, we use the solution given in Example 1 as a parent. We refer to this as Solution1. We use another solution, Solution2, as the second parent.

\section{Solution2:}

\begin{tabular}{|c|c|c|c|c|c|c|c|c|c|c|c|c|}
\hline Node & 1 & 2 & 3 & 4 & 5 & 6 & 7 & 8 & 9 & 10 & 11 & 12 \\
\hline Coding & 1 & 1 & 0 & 1 & 0 & 1 & 1 & 0 & 1 & 1 & 1 & 0 \\
\hline
\end{tabular}

\begin{tabular}{|c|c|c|c|c|c|c|c|c|c|c|c|c|}
\hline Arc & 13 & 14 & 15 & 16 & 17 & 18 & 19 & 20 & 21 & 22 & 23 & 24 \\
\hline $\begin{array}{c}\text { Connected } \\
\text { nodes }\end{array}$ & 1,4 & 1,5 & 1,6 & 1,7 & 2,4 & 2,5 & 2,6 & 2,7 & 3,4 & 3,5 & 3,6 & 3,7 \\
\hline Coding & 1 & 0 & 0 & 1 & 1 & 0 & 1 & 0 & 0 & 0 & 0 & 0 \\
\hline
\end{tabular}

\begin{tabular}{|c|c|c|c|c|c|c|c|c|c|c|c|c|c|c|c|c|c|c|c|c|}
\hline Arc & 25 & 26 & 27 & 28 & 29 & 30 & 31 & 32 & 33 & 34 & 35 & 36 & 37 & 38 & 39 & 40 & 41 & 42 & 43 & 44 \\
\hline Connected & 4, & 4, & 4, & 4, & 4, & 5, & 5, & 5, & 5, & 5, & 6, & 6, & 6, & 6, & 6, & 7, & 7, & 7, & 7, & 7, \\
nodes & 8 & 9 & 10 & 11 & 12 & 8 & 9 & 10 & 11 & 12 & 8 & 9 & 10 & 11 & 12 & 8 & 9 & 10 & 11 & 12 \\
\hline Selection & 0 & 1 & 1 & 0 & 0 & 0 & 0 & 0 & 0 & 0 & 0 & 1 & 1 & 1 & 0 & 0 & 1 & 0 & 0 & 0 \\
\hline
\end{tabular}

Example 2: Given Solution1 and Solution2, we assume that crossover point is selected after the second supplier. First, only supplier nodes are transferred from parents to the offspring, based on the crossover point.

\begin{tabular}{|c|c|c|c|c|c|c|c|c|c|c|c|c|}
\hline & \multicolumn{3}{|c|}{ Supplier } & \multicolumn{3}{|c|}{ Plant } & \multicolumn{5}{|c|}{ DC } \\
\hline Node & 1 & 2 & 3 & 4 & 5 & 6 & 7 & 8 & 9 & 10 & 11 & 12 \\
\hline Solution1 & $\mathbf{0}$ & $\mathbf{1}$ & 1 & 0 & 0 & 1 & 1 & 1 & 1 & 1 & 0 & 0 \\
\hline Solution2 & 1 & 1 & $\mathbf{0}$ & 1 & 0 & 1 & 1 & 0 & 1 & 1 & 1 & 0 \\
\hline Offspring & $\mathbf{0}$ & $\mathbf{1}$ & $\mathbf{0}$ & & & & & & & & & \\
\hline
\end{tabular}

Second, the arcs between suppliers and plants are transferred from the parent solution corresponding to the supplier origin. In our example, suppliers 1 and 2 are inherited from 
Solution1 and all arcs leaving these suppliers, in Solution1, are also transferred. Same applies for supplier 3.

\begin{tabular}{|c|c|c|c|c|c|c|c|c|c|c|c|c|}
\hline Arc & 13 & 14 & 15 & 16 & 17 & 18 & 19 & 20 & 21 & 22 & 23 & 24 \\
\hline $\begin{array}{c}\text { Connected } \\
\text { nodes }\end{array}$ & 1,4 & 1,5 & 1,6 & 1,7 & 2,4 & 2,5 & 2,6 & 2,7 & 3,4 & 3,5 & 3,6 & 3,7 \\
\hline Solution1 & $\mathbf{0}$ & $\mathbf{0}$ & $\mathbf{0}$ & $\mathbf{0}$ & $\mathbf{0}$ & $\mathbf{0}$ & $\mathbf{1}$ & $\mathbf{0}$ & 0 & 0 & 0 & 1 \\
\hline Solution2 & 1 & 0 & 0 & 1 & 1 & 0 & 1 & 0 & $\mathbf{0}$ & $\mathbf{0}$ & $\mathbf{0}$ & $\mathbf{0}$ \\
\hline Offspring & $\mathbf{0}$ & $\mathbf{0}$ & $\mathbf{0}$ & $\mathbf{0}$ & $\mathbf{0}$ & $\mathbf{0}$ & $\mathbf{1}$ & $\mathbf{0}$ & $\mathbf{0}$ & $\mathbf{0}$ & $\mathbf{0}$ & $\mathbf{0}$ \\
\hline
\end{tabular}

Third, plant nodes are transferred in the following way: If there is at least one arc coming into a plant $i$, then plant $i$ is selected. Otherwise, it is not selected. In this example, since only plant 6 has an incoming arc, it is the only one selected.

\begin{tabular}{|c|c|c|c|c|c|c|c|c|c|c|c|c|}
\hline & \multicolumn{3}{|c|}{ Supplier } & \multicolumn{5}{|c|}{ Plant } & \multicolumn{5}{c|}{ DC } \\
\hline Node & 1 & 2 & 3 & 4 & 5 & 6 & 7 & 8 & 9 & 10 & 11 & 12 \\
\hline Solution1 & 0 & 1 & 1 & 0 & 0 & 1 & 1 & 1 & 1 & 1 & 0 & 0 \\
\hline Solution2 & 1 & 1 & 0 & 1 & 0 & 1 & 1 & 0 & 1 & 1 & 1 & 0 \\
\hline Offspring & 0 & 1 & 0 & $\mathbf{0}$ & $\mathbf{0}$ & $\mathbf{1}$ & $\mathbf{0}$ & & & & & \\
\hline
\end{tabular}

The same sequence of steps is used to generate the set of arcs between the plants and the DCs. And then the DC nodes that have at least one incoming arc are selected. Finally, the arcs between the DCs and customers are generated. In our example, following the steps detailed here, the offspring solution is completed:

\begin{tabular}{|c|c|c|c|c|c|c|c|c|c|c|c|c|c|c|c|c|c|c|c|c|}
\hline Arc & 25 & 26 & 27 & 28 & 29 & 30 & 31 & 32 & 33 & 34 & 35 & 36 & 37 & 38 & 39 & 40 & 41 & 42 & 43 & 44 \\
\hline Connected & 4, & 4, & 4, & 4, & 4 & 5, & 5, & 5, & 5, & 5, & 6, & 6, & 6, & 6, & 6, & 7, & 7, & 7, & 7, & 7, \\
nodes & 8 & 9 & 10 & 11 & 12 & 8 & 9 & 10 & 11 & 12 & 8 & 9 & 10 & 11 & 12 & 8 & 9 & 10 & 11 & 12 \\
\hline Selection & 0 & 0 & 0 & 0 & 0 & 0 & 0 & 0 & 0 & 0 & 1 & 0 & 1 & 0 & 0 & 0 & 0 & 0 & 0 & 0 \\
\hline
\end{tabular}

The same applies if the crossover point corresponds to plants or DCs.

\subsubsection{Mutation}


A mutation operator randomly flips the value of arcs on a randomly selected solution. This randomly selects an unselected arc or it unselects a selected arc. Although this random change can worsen the quality of a solution, it can also allow the algorithm to get out of a local optimum.

\subsection{The Algorithm}

In this section we provide a high level pseudo-code for the multi-objective optimization algorithm, which uses the GA explained further in Appendix A.

Begin

- Calculate best cost by solving IP with (Obj 1)\& constraints (1-12);

- $B C \leftarrow$ value of (Obj 1)at optimal solution;

- Calculate best reliability with GA using IP composed of (Obj 2)\& constraints $(1-12)$;

- $B R \leftarrow$ the highest value of (Obj 2)in the final population of $\mathrm{GA}$;

- for all weight sets in predefined $\left\{\left(w_{c}, w_{r}\right)_{i}\right\}, i=1 \ldots N$

find optimal solution with GA using Multi-objective Linear Program composed of objective function (13) \& constraints (1-12) \& (14-15)

End

\section{PROBLEM SETTING}

\subsection{Implementation Details}

We implemented our algorithms in Python 2.7.3 and used Gurobi 5.0.0 optimization software to solve the integer programs. The tests are performed on a cluster with eight quad-core $2.7 \mathrm{GHz}$ AMD Opteron 8384 processors and 256 GB of RAM.

The parameters of the GA have been set empirically: We used an initial population size of 50 . At each generation, we created 25 new solutions by applying our operators to the current solutions. Parent solutions are selected using the standard normal distribution. The crossover 
point is selected using a uniform distribution defined on the range [0,2]. Mutation is applied with a probability of 0.5 . The algorithm is terminated if the best solution cost is not improved in 100 consecutive generations.

\subsection{Instance Description}

We created an instance on a network with 3 suppliers, 4 plants, 5 DCs, and 5 customers, where each echelon is connected with all possible arcs as shown in Figure 2. Each entity may have a limited capacity, a fixed and variable cost (C) and a reliability index (R), which can have a value between 1 and 10. For instance, Supplier 1 has a capacity of 110, a fixed cost of $\$ 920.68$ and a variable cost/unit of $\$ 4.81$ and a reliability index of 2.83. A higher reliability index means that there is a lower risk associated with that entity. Similarly, the arc between nodes 3 and 7 has a capacity of 350, a fixed cost of $\$ 123.61$, a variable cost/unit of $\$ 0.51$ and a reliability index of 8.11. For clarity of presentation, we only included the data of arc [3, 7] in Figure 2.

The cost, capacity and reliability parameters are carefully set to mimic the realities of today's supply chains and based on extant literature. The main principles we used for the nodes are as follows:

- The capacity of one node in each echelon is set equal to or no less than $95 \%$ of the total demand of customers and the rest are set to significantly less than the demand. This allows for both single and multiple sourcing options as feasible solutions while allowing both full and partial demand satisfaction.

- The fixed cost of a node increases at a decreasing rate as capacity increases, which captures the economies of scale in capital costs (Moore, 1953).

- The variable cost of a node decreases at a decreasing rate as fixed cost increases, which captures the economies of scale in operating costs (Kim et al., 2008). 
- Risk decreases at a decreasing rate as the sum of variable cost and per unit fixed cost (i.e., fixed cost/capacity) increases, which captures the generally established inverse relationship between risk and cost (Chopra and Sodhi, 2014; Lev, 1974; Olson, 2010) and the diminishing rate of returns.

The arcs represent both the transportation between two nodes and also the buyer-supplier relationship between these two nodes. The main principles we used for the arcs, which are based on similar principles used for nodes and supported by related literature, are as follows:

- Capacity of an arc is the same as the capacity of its origin, which means that transportation capacity is not an issue.

- Fixed cost of an arc is independent of the capacity, as there is no major capital investment assumed for transportation and establishing a relationship. The fixed cost may be related to minimum amount charges of carriers or implicit costs due to establishing a new relationship and/or minimum order requirements.

- Variable cost decreases at a decreasing rate as fixed cost increases (Kim et al., 2008).

- Risk decreases at a decreasing rate as variable cost increases (Chopra and Sodhi, 2014; Lev, 1974; Olson, 2010), which implies that premium transportation services that cost more are less risky.

The actual parameters used in this instance and the functions used to generate these parameters are shown in the Appendix B.

\section{RESULTS, DISCUSSION, and MANAGERIAL IMPLICATIONS}

We ran our models for a combination of weights assigned to total cost and total reliability for three different cost and reliability parameter sets. We present detailed discussion of the results for one of these parameter sets (i.e. parameter set 1 as illustrated in Table A-1 in Appendix A) 
and summary findings for the others, based on four formulations for cumulative reliability calculation: no compounding, compounding using "min", "max" and "average” functions. Figure 3 illustrates the tradeoff between total cost and total reliability for a 95\% demand satisfaction level using the four different formulations for parameter set 1 The graphs in Figure 3 are obtained by connecting four solutions corresponding to the same cost-reliability weights for ease of presentation and illustration. We will refer to the three segments of lines connecting these four solutions as segments 1, 2 and 3 from left to right. The first observation we obtain from Figure 3 is the importance of the compounding mechanism to total risk formulation. In this instance, the average reliability of the suppliers is lowest, which is followed by plants and distribution centers. With such a parameter setting, not incorporating the downstream supply chain's reliability inflates the total reliability of the network. Because of this the graph corresponding to noncompounding is significantly apart from the rest of the graphs in Figure 3. Similar disparities are realized as long as the reliability of the nodes across the echelons of the network is different from each other. Figure 3 illustratively justifies the need for using the compounding mechanism that captures the total reliability of a network design in a more accurate manner. The second observation is the rank order among the three compounding mechanisms. As discussed before, the max formulation represents an optimistic view of the impact of downstream supply chain, thus always providing a higher total reliability compared to the average and min formulations. Likewise, the min formulation represents the pessimistic view of the impact of downstream supply chain, thus always providing the lowest total reliability compared to the average and max formulations. In each graph, as the relative weight of reliability increases in the objective function, we are able to obtain more low risk solutions at higher costs. In all four graphs, the cost difference of the two extreme solutions is much larger than the difference in reliability, which is 
better illustrated by the slopes of the graphs in Table 1. All but one of the slopes is strictly less than 1 and decrease as we go from segment 1 to segment 3 . The slope analysis also provides information on how much reliability gain is obtained for a unit dollar spending. For instance, for Parameter set 1 , with the max formulation, each dollar spent initially results in an increase of almost one unit of reliability. This, however, sharply decreases to 0.07 and then to 0.03 , which illustrates diminishing rate of return in reliability gains. Similar trends are observed across the other formulations and other parameter sets as seen in Table 1.

Insert Figure 3 and Table 1 Here

Another interesting observation in Table 1 is the comparison of the formulations. In each parameter set, the non-compounding formulation underestimates the reliability gain obtained in segment 1 of the graphs, in which, the weight of reliability objective increases from zero to a non-zero weight, even though we observe significant design changes due to this weight change. This reinforces the benefit of using a compounding approach over a non-compounding approach.

While subtle differences exist with results associated with the different formulations, the relative consistency associated with the general nature of the tradeoff curves (reliability vs. cost) across the various formulations is evident from our analysis, which validates the general phenomenon under different settings. For a managerial perspective, we provide the decisionmaker with robust options in choosing a formulation that best fits their company's perspective on upstream supply chain's impact on downstream nodes' reliability. In addition, in each of the formulations, we provide the decision-maker with near Pareto optimal solutions that assist in supply network design and operational decisions. We expand on this more in subsequent sections.

We consider Figure 3 in addressing some of the interesting results and related managerial insights. It is evident from Figure 3 that at the lower left corner of each of the four graphs, the 
reliability increases relatively steeply as more weight is assigned to it. For illustrative purposes in our discussion below, we will focus on the solutions obtained by the Average formulation. The solutions are depicted on the networks in Figures 4-6, where a highlighted node represents a node that's selected. The small numbers in the parentheses represents the quantity received by this node from upstream.

In the least costly solution, reliability's weight in the objective function is zero. This results in a solution that consists of using only the lowest costly supplier, plant, and distribution center to serve the customers as shown in Figure 4. Thus, the important managerial implication here is that if a company focuses on cost, the general direction is to move towards having few nodes and arcs that are active and least costly in the supply chain although this comes at the expense of reliability. Once the weight on reliability is increased, the solution obtained utilizes the two reliable suppliers and avoids the least reliable supplier to increase the total reliability of the design, as seen in Figure 5. Since the fixed cost of suppliers is the lowest among all nodes,working with multiple suppliers does not significantly increase the total cost.

\section{Insert Figure 4 and 5 Here}

The structure of the solution also changes significantly by adding more nodes to the supply chain to increase reliability. For instance, we see that plant 4 is used in addition to plant 7 as a means to increase reliability in Figure 5. This is a clear example of a multiple sourcing strategy. When the weight of reliability is increased to $98.8 \%$ and the weight of cost is decreased to $1.2 \%$, the solution follows Figure 6, where the solution now uses multiple sourcing at each echelon, in contrast to single sourcing seen in Figure 4. Increased reliability in the upstream supply chain, especially the supply base, has a significant impact in the compounding formulations as it cascades through the network. 
Insert Figure 6 Here

In addition, when we focus on the actual flow of units for the network in Figure 6, we see that there is a flow of 108 units from Supplier 1 to Plant 5, but only a single unit from Supplier 1 to Plant 4. Similarly, flow from Plant 4 to DC 12 is also only 1 unit. While a flow of a single unit is not practical in an actual setting, this can be interpreted as Plant 4 using Supplier 2 as its main supplier and Supplier 1 as a backup supplier. Similarly, DC 12 uses Plant 8 as its primary source, whereas Plant 4 as a backup source. This type of an arrangement is in line with using backup suppliers as a risk mitigation strategy (e.g., Chopra et al., 2007).

To test the robustness of our formulations, we solve three instances with three different parameters sets. The results for the two compounding formulations are shown in Figure 7, where the results based on the three instances look very similar. This provides assurance about the robustness of our formulations to parameter changes.

Insert Figure 7 Here

\subsection{Managerial Implications}

Several interesting managerial implications emerge from our analysis. First, we find that in situations where companies are interested in a higher level of reliability they must sacrifice cost, but the key question is by how much. As evident from our results, the supply chain becomes denser with more nodes and arcs as we focus on higher levels of reliability. Thus, moving from single sourcing to multiple sourcing is identified as a risk mitigation strategy. Given the level of reliability, our analysis provides a road map for decision-makers in terms of what the corresponding costs are, what supply chain structure must be considered, and how the product must be shipped in achieving the established targets and goals. 
Second, our analysis also identifies fortification solutions in the form of back-up suppliers that companies ought to have in maintaining high levels of reliability, which comes at an extra cost. Thus, from a risk mitigation standpoint, we present structural (selection of nodes) and infrastructural (transportation) options in achieving higher levels of reliability in limiting risk. It is important to note that, the use of back-up suppliers is clearly different from the multiple sourcing options obtained in some of our solutions.

Another factor that has managerial importance is the demand satisfaction. It is interesting to note that differences exist among the solutions obtained from the four formulations in terms of demand satisfaction levels. All formulations result in solutions with complete demand satisfaction when the weight for reliability approaches $100 \%$. This can be explained by the increase in the total reliability objective function value with the increase of flow in the network. However, this is not the case for some of the formulations where the weight on the cost objective is still significant. All solutions obtained with the non-compounding formulation and the "max" compounding formulation have $100 \%$ demand satisfaction, whereas the "min" and "average" compounding formulations result in solutions with shortages in some of the cases such as the one in Figure 5, which has a DS $=97.1 \%$. In Figure 5, shortage (customer B-E) is a direct result of not selecting Supplier 3 in the solution, because the total capacity of Supplier 1 and Supplier 2 is not enough to meet all of the demand. With the "min" compounding approach, Supplier 3's low reliability defines the downstream reliability as this approach emphasizes the least reliable entity in the upstream chain of a node. Similarly, with the "average" compounding, Supplier 3's low reliability still impacts the downstream reliability, although not as much as the "min" case. Thus, the "min" and "average" formulations result in shortages to avoid a highly unreliable supplier. On the other hand, with the optimistic "max" compounding approach, avoiding Supplier 3 does 
not pay-off as much, since the most reliable supplier selected, which is Supplier 1 in that scenario, defines the compounding reliability. With the non-compounding formulation, the reliability gain through increased flow with full demand satisfaction seems to outweigh any gains in the reliability increase in the supply base by avoiding Supplier 3, thus always resulting in 100\% demand satisfaction in all solutions.

The important managerial implication here is that if a company wants to place high importance on demand satisfaction then they must accordingly choose the appropriate formulation as detailed above. In that sense, demand satisfaction and reliability maximization move along the same direction in our formulations. Although not presented in this article, we found that the results seem to be robust to different values of demand satisfaction levels (DSL), with slight increase in total cost as DSL increases.

Finally, we observe that in each of the parameters sets, the risk mitigation strategies are utilized in the following order as the weight of reliability objective is increased: First using reliable suppliers, then using multiple sourcing, and finally using back-up suppliers. This is important as it provides guidance in terms of the order of utilizing various risk mitigation strategies.

\section{CONCLUSIONS AND EXTENSIONS}

This study considers the supply chain network design problem and presents formulations with dual objectives, which usually conflict with each other: minimizing cost and maximizing reliability. Realizing the need for a method to quantify total reliability of a network design for comparing different options based on total reliability and total cost, we propose to assign a reliability index, based on multi-criteria modeling, to each entity and activity. Since the entities in a supply chain are interrelated, we attempt to model the impact of upstream supply chain's 
reliability on the reliability of the downstream entities through three different compounding mechanisms.

This study establishes a clear tradeoff between reliability and cost in supply chain network design. While some differences exist with results associated with the various formulations, the relative robustness associated with the general nature of the tradeoff curves provide managers with options in choosing a formulation that best fits their company's perspective on upstream supply chain's impact on downstream nodes' reliability.

In choosing among the formulations, another factor that might be considered is the importance of demand satisfaction as the formulations differ in the solutions they produce in that aspect. In general, we observe that demand satisfaction and reliability maximization move along the same direction in our formulations. However, when capacity of reliable suppliers is limited, some formulations result in solutions with shortages to maximize reliability.

Our work also identifies possible risk mitigation strategies implied by the solutions obtained in our analysis. The first strategy is using more reliable suppliers. Second is moving from single sourcing to multiple sourcing. The network structure of the solutions reveals that the supply chain becomes denser with more nodes and arcs as we focus on higher levels of reliability. The third strategy is having back-up suppliers, even though no sourcing is made from those suppliers.

While this study makes significant advances in the research of reliable supply chain network design, it is not devoid of limitations. First, we use a single value to represent the reliability of each entity and activity, which may result in loss of information due to aggregation. However, our research can easily be extended to have multiple reliability measures by decoupling different characteristics of one risk from another type of risk as suggested by Chopra et al. (2007). 
Although we were able to obtain tradeoff curves that suggest Pareto efficiency, we cannot claim we actually achieved Pareto optimality since we used a Genetic Algorithm to obtain solutions. This was because of the non-linearity of our models. An improvement in the solution methodology that would guarantee optimality of the solutions would be useful in characterizing the actual Pareto frontier.

Finally, the use of real data to validate our methodology and analysis would be useful. Although the instance we solve is not based on real data, the parameters for the instance are

carefully selected as described in Appendix B. In the same tone, while we do not actually apply the AHP approach in determining the reliability indices, the framework to use this technique is explained.

One other future research direction can be using Neureuter and Kenyon (2008)'s risk index definition focusing on disruptions and the time it would take for each node to be restored to full functionality after a disruption. Integrating this time to recovery data with information on operational and financial measures, one can assign a financial performance impact of the disruption to each node along the supply chain. This approach can provide a number of benefits in terms of managerial insights. It can, for example, assist in identifying the previously hidden nodes in the network that create the greatest risk exposure, to compare the costs and benefits of different alternatives for mitigating impact, and to make inventory and sourcing decisions that increase the robustness of the network.

\section{REFERENCES}

Andreas, A. K., Smith, J. C., and Küçükyavuz, S. (2008). Branch-and-price-and-cut algorithms for solving the reliable h-paths problem. Journal of Global Optimization, 42(4), 443-466. 
Axsäter, S. (1993). Continuous review policies for multi-level inventory systems with stochastic demand. In: Graves, S. C., Rinnooy Kan, A. H., Zipkin, P. H., (Eds). Logistics of Production and Inventory. North-Holland Publishing Company, Amsterdam.

Berger, P. D., Gerstenfeld, A., and Zeng, A.Z. (2004). How many suppliers are best? A decision analysis approach. Omega, 32, 9-15.

Blackhurst, J.V., Scheibe, K.P., and Johnson, D.J. (2008). Supplier risk assessment and monitoring for the automotive industry. International Journal of Physical Distribution and Logistics Management, 38, 143-165.

Bogataj, D., and Bogataj, M. (2007). Measuring the supply chain risk and vulnerability in frequency space. International Journal of Production Economics, 108, 291-301.

Bundschuh, M., Klabjan, D., and Thurston, D. (2006) Modeling robust and reliable supply chains, University of Illinois at Urbana-Champaign.

Carvinato, J.L. (2004). Supply chain logistics risks: From the back room to the board room. International Journal of Physical Distribution and Logistics Management, 34, 383-387.

Chen, A., Kim, J., Zhou, Z., and Chootinan, P. (2007). Alpha reliable network design problem. Transportation Research Record: Journal of the Transportation Research Board, 2029(1), 49-57.

Chopra, S., Reinhardt, G., and Mohan, U. (2007). The importance of decoupling recurrent and disruption risks in a supply chain. Naval Research Logistics, 54(5), 544-555.

Chopra, S., and Sodhi, M.S., (2004). Managing risk to avoid supply-chain breakdown. MIT Sloan Management Review, 46, 53-62.

Christopher, M., and Peck, H. (2004). Building the resilient supply chain. The International Journal of Logistics Management, 15, 1-13.

Colicchia, C., and Strozzi, F. (2012). Supply chain risk management: A new methodology for a systematic literature review. Supply Chain Management: An International Journal, 17, 403418.

Costa, L., and Oliveira, P. (2001). Evolutionary algorithms approach to the solution of mixed integer non-linear programming problems. Computers \& Chemical Engineering, 25(2), 257-266.

Davis, T. (1993). Effective supply chain management. Sloan Management Review, Summer, 3546.

Deb, K. (2001). Nonlinear goal programming using multi-objective genetic algorithms. Journal of the Operational Research Society, 291-302. 
Desai, J., and Sen, S. (2010). A global optimization algorithm for reliable network design. European Journal of Operational Research, 200(1), 1-8.

Diks, E. B., De Kok, A. G., and Lagodimos, A. G. (1996). Multi-echelon systems: A service measure perspective. European Journal of Operational Research, 95, 241-263.

Federgruen, A. (1993). Centralized Planning model for multi-echelon inventory systems under uncertainty. In: Graves, S. C., Rinnooy Kan, A. H., Zipkin, P. H., (Eds). Logistics of Production and Inventory. North-Holland Publishing Company, Amsterdam.

Georgiadis, M.C., Tsiakis, P., Longinidis, P., and Sofioglou, M.K. (2011). Optimal design of supply chain networks under uncertain transient demand variations. Omega, 39, 254-272.

Goetschalckx, M. (2000). Strategic network planning. In: Stadtler, H. and Kilger, C., (Eds). Supply Chain Management and Advanced Planning: Concepts, Models, Software and Case Studies. Springer, Berlin, 79-95.

Goldberg, D.E. (1989). Genetic Algorithms in Search, Optimization and Machine Learning. Addison-Wesley Professional

Goldberg, D. E. (1991). Real-coded genetic algorithms, virtual alphabets, and blocking. Complex Systems 5(2), 139-168

Graves, S. C. (1987). Safety stocks in manufacturing systems. Journal of Manufacturing and Operations Management. 1(1), 67-101.

Grosfeld-Nir, A. and Gerchak, Y. (2004). Multiple lotsizing in production to order with random ields: Review of recent advances. Annals of Operations Research, 126(1), 43-69.

Gümüş, M., Ray, S., and Gurnani, H. (2012). Supply-side story: Risks, guarantees, competition, and information asymmetry. Management Science, 58(9), 1694-1714.

Gupta, A. and Maranas, C. D. (2003). Managing demand uncertainty in supply chain planning. Computers and Chemical Engineering, 27, 1219-1227.

Gurnani, H., Akella, R., and Lehoczky, J. (2000). Supply mangement in assembly systems with random yield and random demand. IIE Transactions, 32, 701-714.

Harland, C., Brenchley, R., and Walker, H. (2003). Risk in supply networks. Journal of Purchasing and Supply Management, 9, 51-62.

He, Y. and Zhang, J. (2008). Random yield risk sharing in a two-level supply chain. International Journal of Production Economics, 112(2), 769-781.

Hendricks, K. B., and Singhal, V. R. (2003). The effect of supply chain glitches on shareholder wealth. Journal of Operations Management, 21(5), 501-522. 
Hendricks, K. B., and Singhal, V. R. ${ }^{\text {a }}$ (2005). Association between supply chain glitches and operating performance. Management Science, 51(5), 695-711.

Hendricks, K. B., and Singhal, V. R. (2005). An empirical analysis of the effect of supply chain diruptions on long-run stock price performance and equity risk of the firm. Production and Operations Management, 14(1), 35-52.

Holland, J. H. (1975). Adaptation in natural and artificial systems: An introductory analysis with applications to biology, control, and artificial intelligence. U Michigan Press.

Inderfurth, K. (1994). Safety stocks in multistage, divergent inventory systems: A survey. International Journal of Production Economics, 35, 321-329.

Jüttner, U., Peck, H., and Christopher, M. (2003). Supply chain risk management: Outlining an agenda for future research. International Journal of Logistics: Research and Applications, 6, 197-210.

Khorramshahgol, R., Azani, H, and Gousty, Y. (1998). An integrated approach to project evaluation and selection. IEEE Transactions on Engineering Management, 35, 265-270.

Kim, S.L., Banerjee, A., and Burton, J., 2008. Production and delivery policies for enhanced supply chain partnerships. International Journal of Production Research, 46, 6207-6229.

Klibi, W., Martel, A., and Guitouni, A. (2010). The design of robust value-creating supply chain networks: a critical review. European Journal of Operational Research, 203(2), 283-293.

Knemeyer, A.M., Zinn, W., and Eroglu, C. (2009). Proactive planning for catastrophic events in supply chains. Journal of Operations Management, 27, 141-153.

Kull, T.J., and Talluri, S. (2008). A supply risk reduction model using integrated multicriteria decision making. IEEE Transactions on Engineering Management, 55(3), 409-419.

Kumar, S.K., Tiwari, M.K., and Babiceanu, R.F. (2010). Minimisation of supply chain cost with embedded risk using computational intelligence approaches. International Journal of Production Research, 48(13), 3717-3739.

Lev, B., (1974). On the association between operating leverage and risk. Journal of Financial and Quantitative Analysis, 9, 627-641.

Li, J., Wang, S.Y., and Cheng, T.C.E. (2010). Competition and cooperation in a single-retailer two-supplier supply chain with supply disruption. International Journal of Production Economics, 124, 137-150.

Lin, Y. C., Wang, F. S., and Hwang, K. S. (1999). A hybrid method of evolutionary algorithms for mixed-integer nonlinear optimization problems. In Evolutionary Computation, 1999. CEC 99. Proceedings of the 1999 Congress on (Vol. 3). IEEE. 
Lin, Y., and Zhou, L. (2011). The impacts of product design changes on supply chain risk: A case study. International Journal of Physical Distribution and Logistics Management, 41, 162-186.

Liu, Z.G., and Nagurney, A. (2011). Supply chain outsourcing under exchange rate risk and competition. Omega, 39, 539-549.

Liu, Y., and Tipper, D. (2001). Successive survivable routing for node failures. In Global Telecommunications Conference, 2001. GLOBECOM'01. IEEE , 4, 2093-2097.

Manuj, I., and Mentzer, J.T. (2008). Global supply chain risk management strategies. International Journal of Physical Distribution and Logistics Management, 38, 192-223.

Martha, J., and Vratimos, E. (2002). Creating a just-in-case supply chain for the inevitable next disaster. Mercer Management Journal, 14, 70-77.

Meena, P.L., Sarmah, S.P., and Sarkar, A. (2011). Sourcing decisions under risks of catastrophic event disruptions. Transportation Research Part E, 47, 1058-1074.

Moore, F. T. (1959). Economies of scale: Some statistical evidence. The Quarterly Journal of Economics, 73(2), 232-245.

Narasimhan, R., and Talluri, S. (2009). Perspectives on risk management in supply chains. Journal of Operations Management, 27, 114-118.

Naylor, J. B., Naim, M. M., and Berry, D. (1999). Leagility: Integrating the lean and agile manufacturing paradigms in the total supply chain. International Journal of Production Economics, 62, 107-118.

Neureuther, B., and Kenyon, G. (2008). A Model for Evaluating Supply Chain Risk. Available at SSRN 1140658, http://papers.ssrn.com/sol3/papers.cfm?abstract_id=1140658, last accessed on July 52014.

O’Keeffe, P. (2006). Understanding supply chain risk areas, solutions, and plans: a five-paper series. APICS, The Association of Operations Management, Alexandria, VA.

Olson, D.L., and Wu, D.D. (2010). A review of enterprise risk management in supply chain. Kybernetes, 39, 694-706.

Olson, E.G., (2010). Supply chain opportunity in an uncertain economic recovery. Supply Chain Management: An International Journal, 15, 488-492.

Parlar, M., and Wang, D. (1993). Diversification under yield randomness in inventory models. European Journal of Operational Research, 66(1), 52-64.

Parlar, M. and Perry, D. (1995), Analysis of a (Q, r, T) Inventory Policy with Deterministic and Random Yields When Future Supply is Uncertain. European Journal of Operational Research, 84(2), 431-443. 
Parlar, M. (1997). Continuous-Review Inventory Problem with Random Supply Interruptions. European Journal of Operational Research, 99(1), 366-385.

Qi, L., Shen, Z. J. M., and Snyder, L. V. (2010). The effect of supply disruptions on supply chain design decisions. Transportation Science, 44(2), 274-289.

Qiang, P., and Nagurney, A. (2012). A bi-criteria indicator to assess supply chain network performance for critical needs under capacity and demand disruptions. Transportation Research Part A, 46, 801-812.

Rao, S., and Goldsby, T.J. (2009). Supply chain risks: A review and typology. The International Journal of Logistics Management, 20, 97-123.

Ravindran, A.R., Bilsel, R.U., Wadhwa, V., and Yang, T. (2010). Risk adjusted multicriteria supplier selection models with applications. International Journal of Production Research, 48, 405-424.

Ruiz-Torres, A.J., and Mahmoodi, F. (2007). The optimal number of suppliers considering the costs of individual supplier failures. Omega, 35, 104-115.

Saaty, T. L. (1988). Decision Making for Leaders: The Analytical Hierarchy Process for Decisions in a Complex World. Pittsburgh, PA: RWS.

Schmitt, A.J., Snyder, L.V., and Shen, Z.J.M. (2010). Inventory systems with stochastic demand and supply: Properties and approximations. European Journal of Operational Research, 206, 313-328.

Schmitt, A.J. (2011). Strategies for customer service level protection under multi-echelon supply chain disruption risk. Transportation Research Part B, 45, 1266-1283.

Schwarz, L. B. (1989). A model for assessing the value of warehouse risk-pooling: Risk pooling over outside-supplier leadtimes. Management Science, 35, 828-842.

Schwarz, L. B. and Weng, Z. K. (2000). The design of a JIT supply chain: The effect of leadtine ucertainty on safety stock. Journal of Business Logistics, 21, 231-253.

Snyder, L. V., Atan, Z., Peng, P., Rong, S., Ying, A. J., and Sinsoysal, B. (2010). Or/ms models for supply chain disruptions: A review.

Sheffi, Y. (2001). Supply chain management under the threat of international terrorism. International Journal of Logistics Management, 12(2), 1-11.

Shi, Y., Wu, F., Chu, L.K., Sculli, D., and Xu, Y.H. (2011). A portfolio approach to managing procurement risk using multi-stage stochastic programming. Journal of the Operational Research Society, 62, 1958-1970.

Simchi-Levi, D., Kaminsky, P., and Simchi-Levi, E. (2004). Managing the supply chain: the definitive guide for the business professional. McGraw-Hill Companies. 
Sivanandam, S. N., and Deepa, S. N. (2008). Genetic Algorithm Optimization Problems (pp. 165-209). Springer Berlin Heidelberg.

Snyder, L. V., and Daskin, M. S. (2005). Reliability models for facility location: the expected failure cost case. Transportation Science, 39(3), 400-416.

Sodhi, M. S. and Tang, C.S. (2012). Managing Supply Chain Risk. Springer Verlag, NewYork, NY.

Sodhi, M.S., Son, B.G, and Tang, C.S. (2012). Researchers' perspectives on supply chain risk management. Production and Operations Management, 21, 1-13.

Tang, C.S. (2006). Perspectives in Supply Chain Risk Management. International Journal of Production Economics, 103(2), 451-488.

Tang, O., and Musa, S. N. (2011). Identifying risk issues and research advancements in supply chain risk management. International Journal of Production Economics, 133, 25-34.

Tang, C.S., and Tomlin, B. (2008). The power of flexibility for mitigating supply chain risks. International Journal of Production Economics, 116, 12-27.

Tomlin, B. (2006). On the value of mitigation and contingency strategies for managing supply chain disruption risks. Management Science, 52(5), 639-657.

Trkman, P., and McCormack, K. (2009). Supply chain risk in turbulent environments - A conceptual model for managing supply chain network risk. International Journal of Production Economics, 119, 247-258.

Tsai, C.Y. (2008). On supply chain cash flow risks. Decision Support Systems, 44, 1031-1042.

Tummala, R., and Schoenherr, T. (2011). Assessing and managing risks using the supply chain risk management process (SCRMP). Supply Chain Management: An International Journal, 16, 474-483.

Vakharia, A.J. and Yenipazarli, A. (2009). Managing Supply Chain Disruptions. Foundations and Trends in Technology, Information, and Operations Management, 2:243-325.

Van Houtum, G. J., Inderfurth, K., and Zijm, W. H. J. (1996). Materials coordination in stochastic multi-echelon systems. European Journal of Operational Research, 95, 1-23.

Vidal, C. J., and Goeschalckx, M. (1997). Strategic production-distribution models: A critical review with emphasis on global supply chain models. European Journal of Operational Research, 98(1), 1-18.

Vidal, C. J., and Goeschalckx, M. (2000). Modeling the effect of uncertainties on global logistics systems. Journal of Business Logistics, 21, 95-120. 
Wagner, S.M., and Bode, C. (2008). An empirical examination of supply chain performance along several dimensions of risk. Journal of Business Logistics, 29, 307-325.

Wu, T., Blackhurst, J., and Chidambaram, V. (2006). A model for inbound supply risk analysis. Computers in Industry, 57, 350-365.

Yano, C. and Lee, H. (1995). Lot-sizing with random yields: a review. Operations Research, 43(3), 311-334.

Yokota, T., Gen, M., and Li, Y. X. (1996). Genetic algorithm for non-linear mixed integer programming problems and its applications. Computers \& industrial engineering, 30(4), 905-

917.

Yoon, J., Talluri, S., and Yildiz, H. (2014). Risk mitigation strategy selection methodology in forming the supply base. Working Paper.

Yu, H.S., Zeng, A.Z., and Zhao, L.D. (2009). Single or dual sourcing: Decision-making in the presence of supply chain disruption risks. Omega, 37, 788-800.

Zabarankin, M., Uryasev, S., and Pardalos, P. (2001). Optimal risk path algorithms, 273-298. Springer US.

Zipkin, P. (2000). Foundations of inventory management. McGraw-Hill.

Zsidisin, G. A., Ellram, L. M., Carter, J. R., and Cavinato, J. L. (2004). An analysis of supply risk assessment techniques. International Journal of Physical Distribution \& Logistics Management, 34(5), 397-413.

\section{APPENDIX A: Pseudo-code for the GA}

Begin

- set generation $t \leftarrow 0$ and initialize the population, $p n(0)$, of parents;

- while $t==$ target number of generations

o for all parents in $p n(t)$;

- calculate objective by solving optimization programming;

o recombine parents in $p n(t)$ to yield the population of crossover-offspring, $c(t)$;

o modify the parents in $p n(t)$ to yield the population of mutant-offspring, $m(t)$; 
o select good parents from $p n(t)$ based on objective function value at their optimal solution;

$o p n(t+1) \leftarrow\{$ selected parents in $p n(t)\} \cup c(t) \cup m(t)$;

$o t \longleftarrow t+1$

End

APPENDIX B: The Test Instance

Insert Table A-1 Here

Node capacities: In the parameter set 1 , we assign the largest capacity of single (i) supplier, (ii) plant, and (iii) DC at total demand, and we set the capacity of (iv) sum of the rest of the suppliers, (v) sum of the rest of the plants, and (vi) sum of the rest of the DCs at strictly less than total demand. Subtracting some volumes from each node capacity in parameter set 1 modifies the node capacities in parameter sets 2 and 3.

\section{Insert Figure 8}

Fixed costs for nodes: We assume that fixed cost is increasing with decreasing rate as capacity increases and we use a log-function to represent this relationship. In parameter set 1 , the ranges of supplier fixed cost, plant fixed cost, and DC fixed cost are [900, 1125], [2700, 3375], and [1800, 2250], respectively.

$$
\begin{aligned}
& \min [\text { range }] \pm \varepsilon_{L}=A_{e} \cdot \ln \left([\min \{\text { capacity }\}]^{C_{e}} \cdot B_{e}\right) \\
& \max [\text { range }] \pm \varepsilon_{U}=A_{e} \cdot \ln \left([\max \{\text { capacity }\}]^{C_{e}} \cdot B_{e}\right)
\end{aligned}
$$

,where $\varepsilon_{L}$ and $\varepsilon_{U}$ are random disturbance of lower bound and upper bound respectively and they are small enough, i.e., $0 \leq \varepsilon_{L}, \varepsilon_{U} \leq 25 . A_{e}, B_{e}$, and $C_{e}$ are positive random parameters and 
subscript $e$ stands for echelons, $e=\{$ supplier, plant, DC $\}$. Substituting capacities of parameter set 2 and 3 modifies fixed costs of the parameter sets.

\section{Insert Figure 9 \& 10 Here}

Variable costs for nodes: We assume that variable cost is decreasing with decreasing rate as fixed cost increases and we use a reverse log-function to capture this relationship. In parameter set 1 , the ranges of supplier variable costs, plant variable costs, and DC variable costs are [4, 5], $[4,5]$, and $[1,1.25]$ respectively.

$$
\begin{aligned}
& \min [\text { range }] \pm \varepsilon_{L}=D_{e}-A_{e} \cdot\left[\ln \left([\max \{\text { fixed cost }\}]^{C_{e}} \cdot B_{e}\right)\right] \\
& \max [\text { range }] \pm \varepsilon_{U}=D_{e}-A_{e} \cdot\left[\ln \left([\min \{\text { fixed cost }\}]^{C_{e}} \cdot B_{e}\right)\right]
\end{aligned}
$$

, where $D_{e}$ is random parameter. Substituting fixed costs of parameter set 2 and 3 modifies variable costs of the parameter seta.

Reliability Indices for Nodes: We assume that reliability is increasing with decreasing rate as sum of variable costs and per unit fixed cost (i.e., fixed cost / capacity) increases and we use a log-function to represent this relationship. In parameter set 1 , the ranges of supplier reliability, plant reliability, and DC reliability are [1, 3], [4.5, 6.6], and [8, 10], respectively.

$$
\begin{aligned}
& \min [\text { range }] \pm \varepsilon_{L}=A_{e} \cdot\left[\ln \left([\min \{\text { average cost }\}]^{C_{e}} \cdot B_{e}\right)\right]-D_{e} \\
& \max [\text { range }] \pm \varepsilon_{U}=A_{e} \cdot\left[\ln \left([\max \{\text { average cost }\}]^{C_{e}} \cdot B_{e}\right)\right]-D_{e}
\end{aligned}
$$

, where average cost $=$ variable cost $+\frac{\text { fixed cost }}{\text { capacity }}$. Substituting variable and fixed costs and capacities of parameter set 1 and 2 modifies reliability of the parameter sets.

Insert Table A-2 Here

Fixed costs for arcs: We assume that fixed cost for arcs is independent of the capacity. Thus, this fixed cost is generated by uniform distribution with support [100, 125]. 
Insert Figure $11 \& 12$ Here

Variable costs for arcs: We assume that variable cost is decreasing with decreasing rate as fixed cost increases. And the ranges of the supplier-plant variable cost, plant-DC variable cost, and DC-customer variable cost are [0.5, 0.625], [1, 1.25], and [1, 1.25] respectively. We apply reverse (L2) for this case as we executed in node variable cost generation. Note that we round off the variable costs to the nearest hundredths to reduce the computational time.

Reliability indices for arcs: We assume that reliability is increasing with decreasing rate as variable cost increases. We further assume that across echelons, the reliability indices are comparable. So, all the ranges of arc reliabilities are [1, 3]. We apply log-function for this as follows.

$$
\begin{aligned}
& \min [\text { range }] \pm \varepsilon_{L}=A_{e} \cdot\left[\ln \left(\min \{\text { variable cost }\}^{C_{e}} \cdot B_{e}\right)\right]-D_{e} \\
& \max [\text { range }] \pm \varepsilon_{U}=A_{e} \cdot\left[\ln \left(\max \{\text { variable cost }\} C_{e} \cdot B_{e}\right)\right]-D_{e}
\end{aligned}
$$

\section{APPENDIX C: A Framework for Assigning Reliability Indices}

Many reliability capturing models, including qualitative and quantitative approaches appear in the literature (e.g. Zsidisin et al., 2004; Tomlin, 2006; Chopra et al., 2007). Even with the large number of proposed models, capturing reliability remains problematic and few models have gained wide acceptance. The criteria in reliability assessment are often difficult to quantify and evaluate. In general, many reliability indices used in the literature make strong assumptions such as the underlying probability distribution, fail to reflect the multi-faceted nature of reliability (multiple interrelated criteria) and are generally difficult to operationalize.

Analytical Hierarchy Process (AHP) is one of the techniques that can be utilized for reliability assessment by considering qualitative scales (Saaty, 1988). Instead of using exact numbers, phrases such as "strongly more important than" can be used to extract the decision- 
makers' preferences. Kull and Talluri (2008) provide a good illustration of AHP to assess suppliers' reliability (risk). Although the methodology in Kull and Talluri (2008) focuses only on assessing suppliers' reliability (risk), this can be easily applied to a supply chain network setting by observing that every echelon in the supply chain is a supplier to the next tier in the downstream. Thus, a sequential tier by tier application of the AHP-type approach is suggested. By modifying and utilizing the AHP construct illustrated in Figure 11, the reliabilities of entities in plant and DC levels can also be assessed. Table A-3 presents various risk factors that are identified through interviews and discussions with the supply chain executives of a Fortune 500 apparel firm, which was in the process of redesigning its supply chain network for one of its product lines currently produced in Asia.

While we do not actually apply the AHP approach in determining the reliability scores of various nodes and arcs in our network, as discussed above, such an approach has already been addressed in the literature and can easily be utilized in determining the relative reliability scores for each of the entities on a scale of 0 to 1 and be mapped into a scale of 1 to 10 as utilized in our study.

Insert Figure 13 \& Table A-3 Here

Figures and Tables

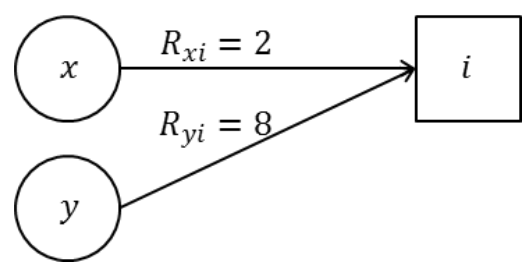

Figure 1: Example for reliability compounding 


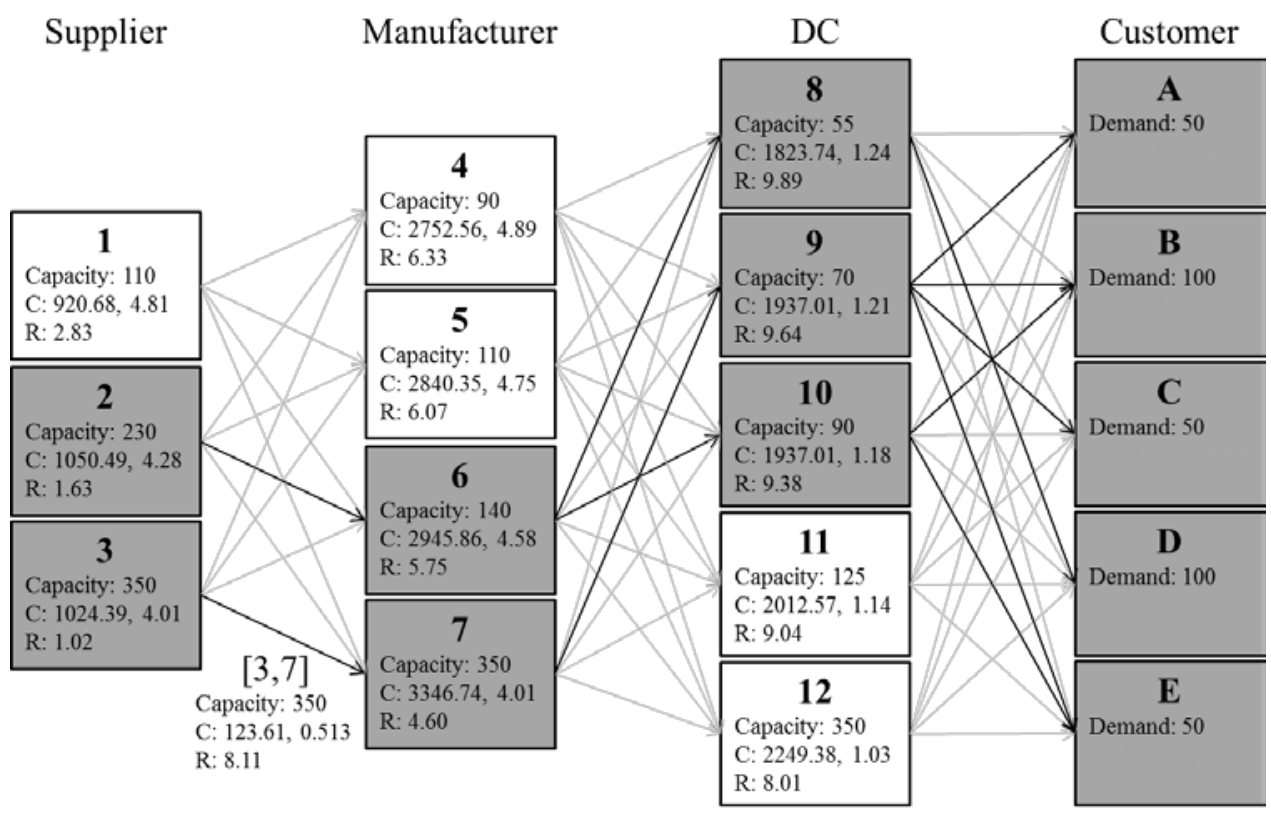

Figure 2: Network representation of a sample solution of instance with 3 suppliers, 4 plants, 5 DC's and 5 customers. C stands for fixed and variable costs, R stands for the reliability index. White boxes and blurred lines represent unselected nodes and arcs respectively.

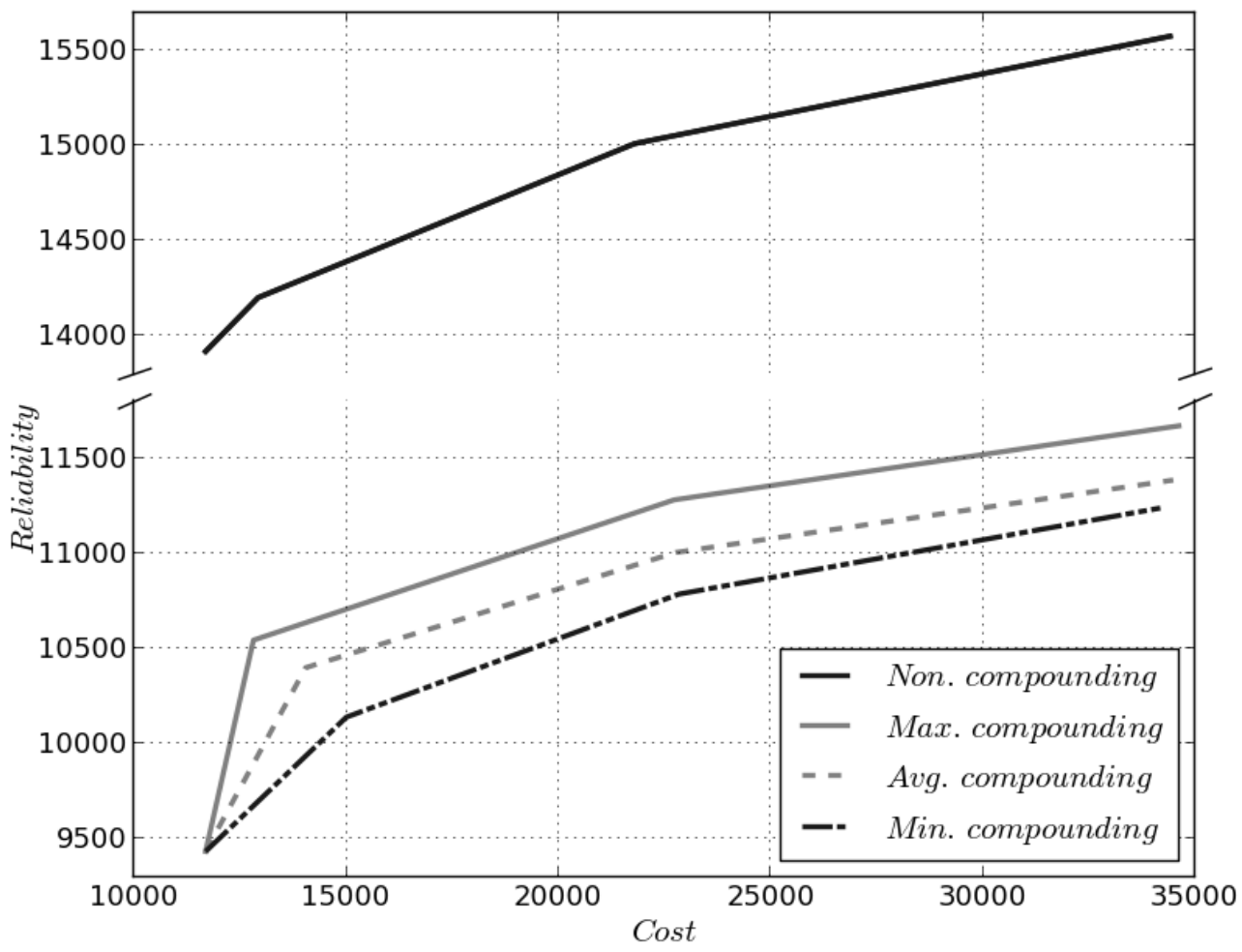

Figure 3: Trade-off between cost and reliability based on four formulations 

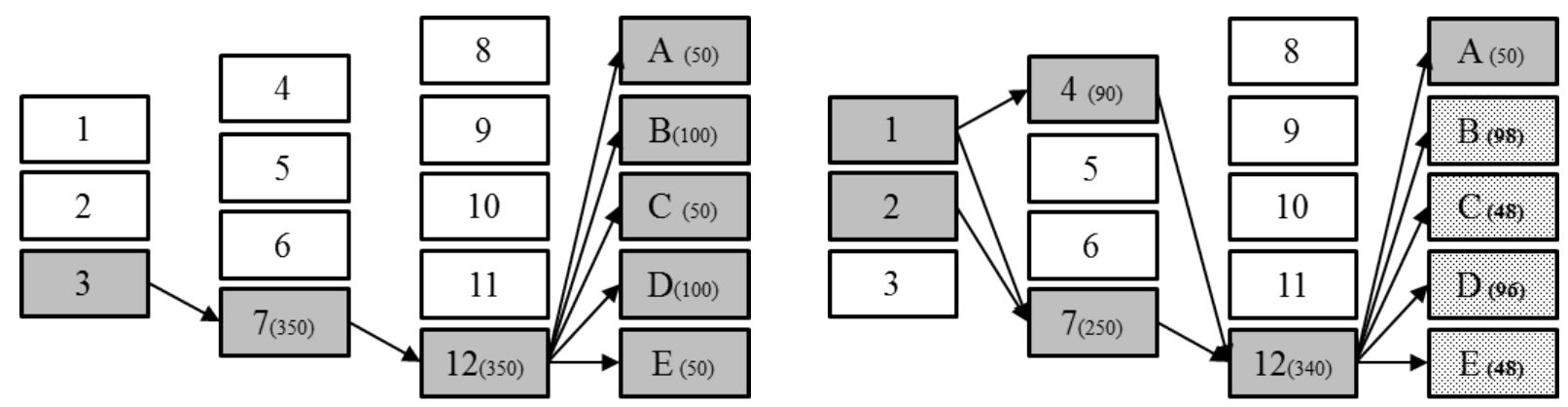

Figure 4: Least costly solution for "avg." compounding of parameter set 1 (delivered Qty.)

Figure 5: Fourth least costly for "avg." compounding of parameter set 1 (delivered Qty.)

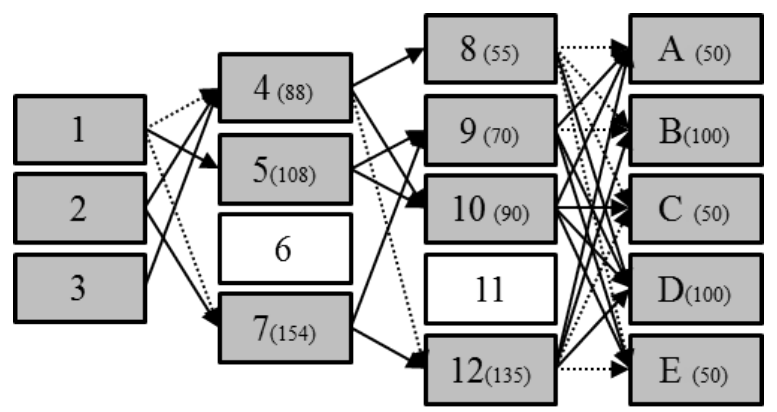

Figure 6: Solution with "avg.” compounding with reliability weight $98.8 \%$ in parameter set 1 . Dashed lines represent backup sourcing (delivered Qty.)
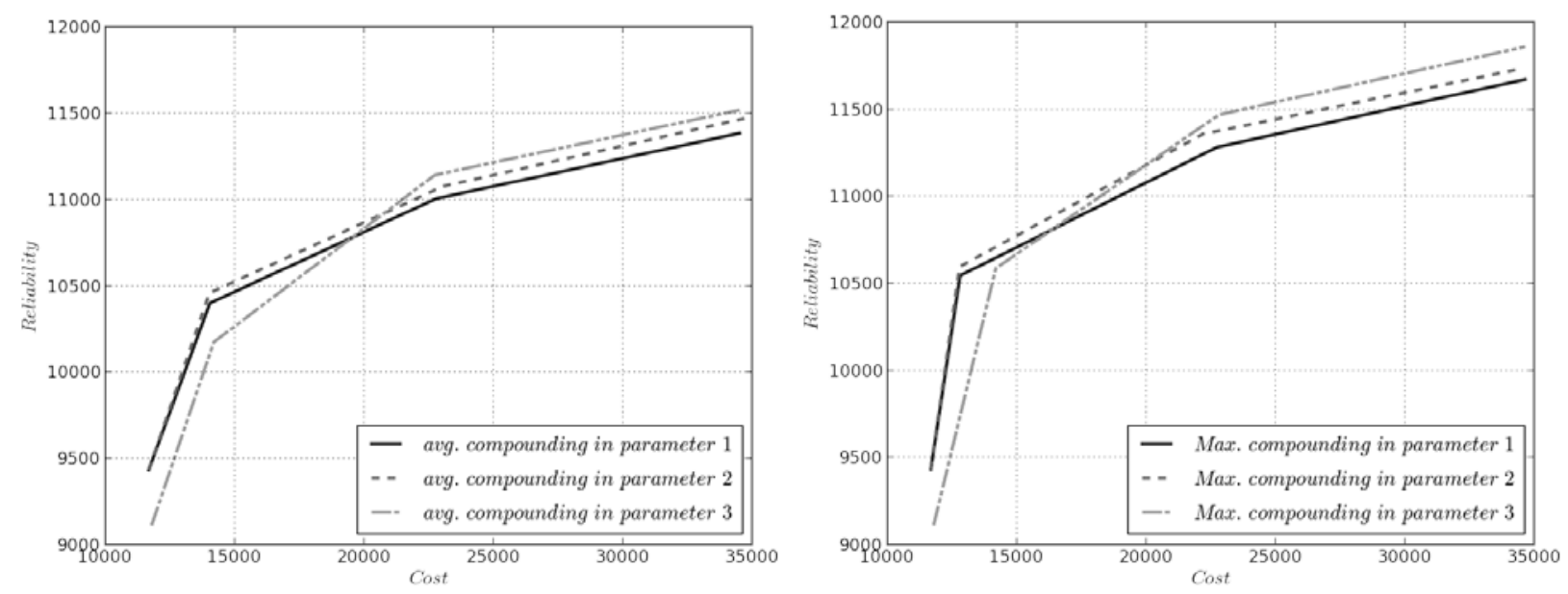

Figure 7: Solution with “avg.” and “max” compounding. 

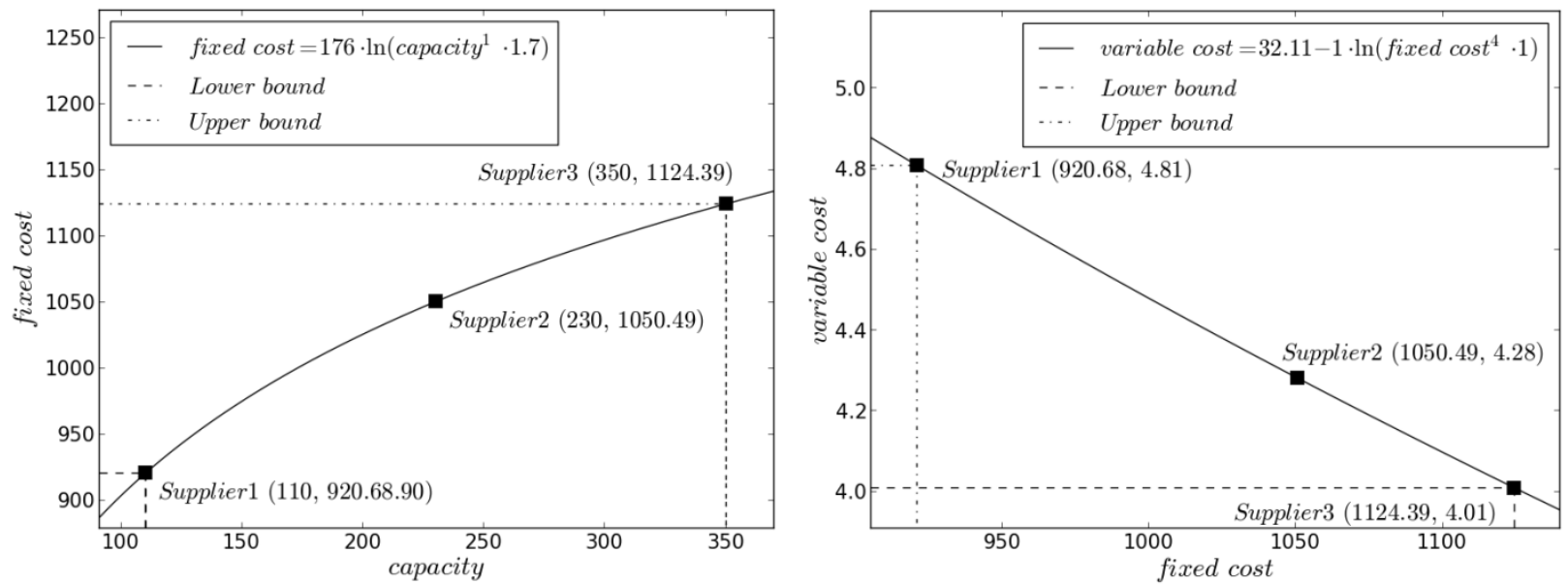

Figure 8: Example of fixed cost for supplier nodes in Figure 9: Example of variable cost supplier nodes in parameter set 1
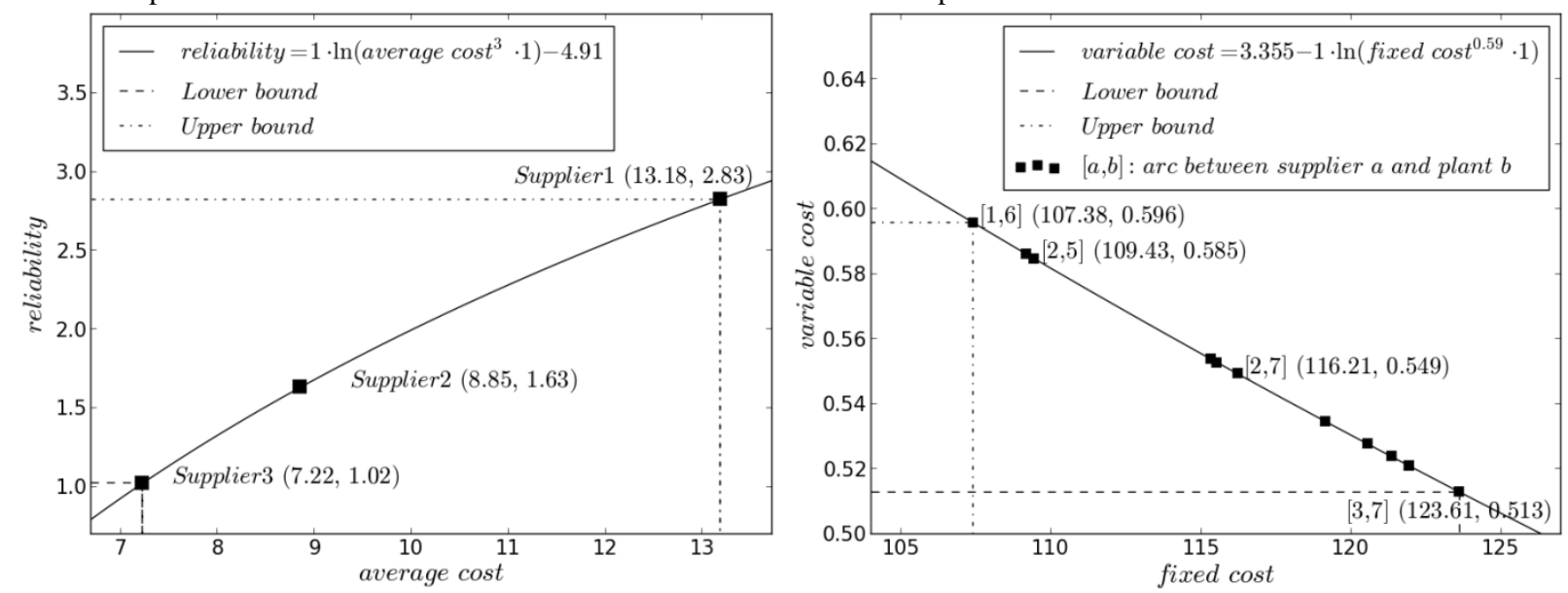

Figure 10: Example of reliability for supplier nodes in Figure 11: Example of variable cost for arcs between supplier parameter set 1

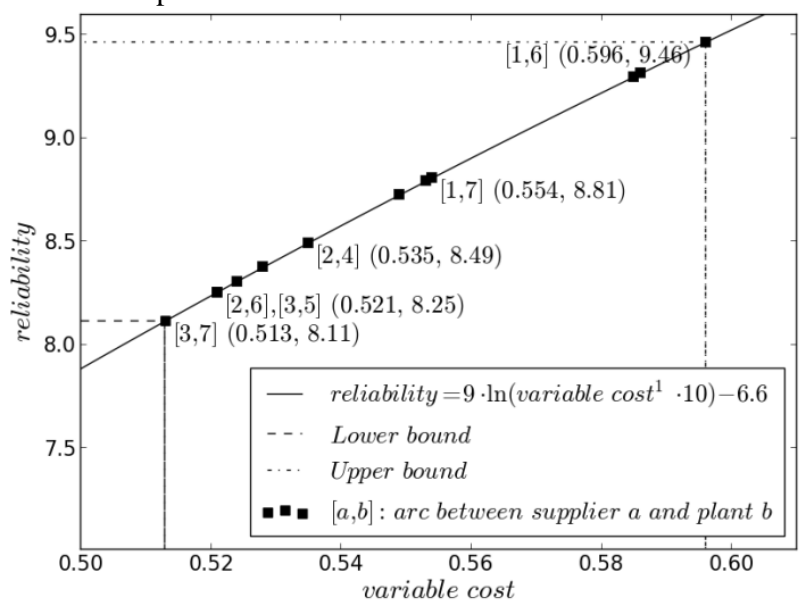
and plant

Figure 12: Example of reliability for arcs between supplier and plant 


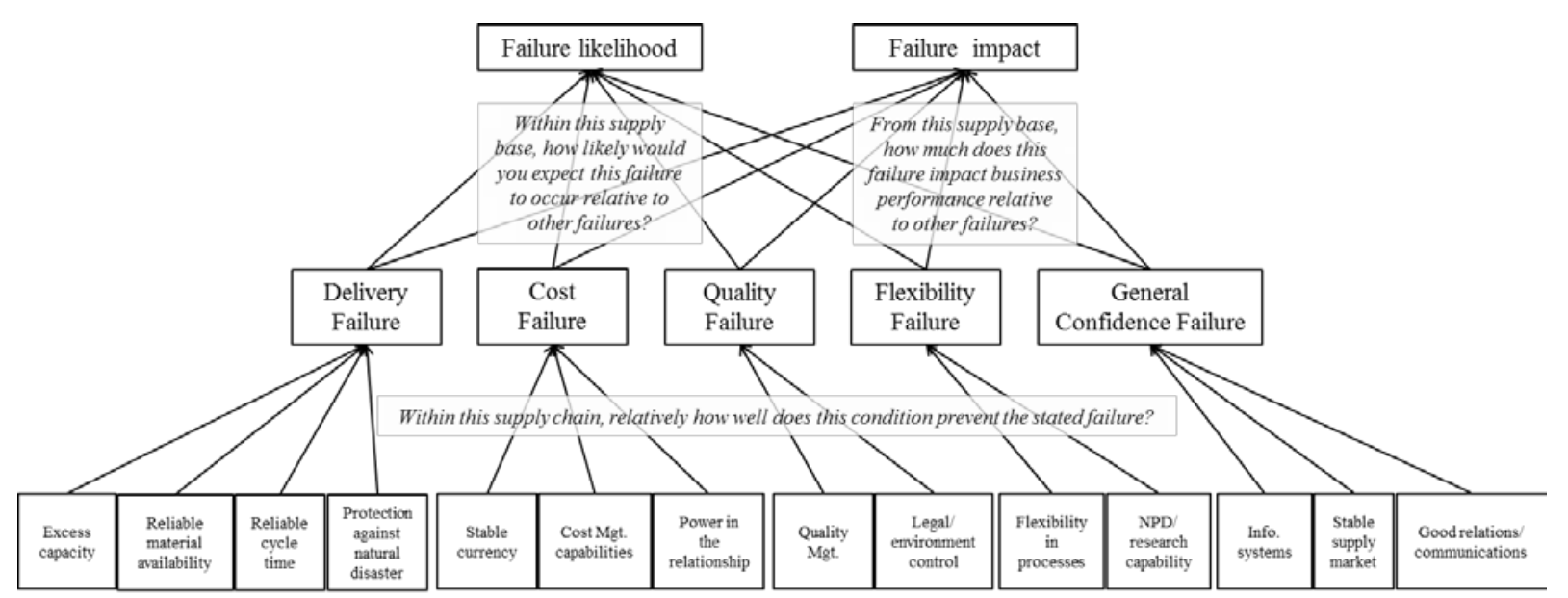

How well does this supplier outperform other suppliers regarding this characteristics?

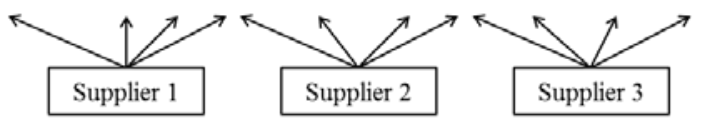

Figure 13: Example of AHP for evaluating supplier risk (Kull \& Talluri, 2008)

\begin{tabular}{|l|c|c|c|c|c|c|c|c|c|}
\cline { 2 - 10 } \multicolumn{1}{c|}{} & \multicolumn{3}{c|}{ Parameter set 1 } & \multicolumn{3}{c|}{ Parameter set 2 } & \multicolumn{3}{c|}{ Parameter set 3 } \\
\cline { 2 - 11 } \multicolumn{1}{c|}{} & Seg. 1 & Seg. 2 & Seg. 3 & Seg. 1 & Seg. 2 & Seg. 3 & Seg. 1 & Seg. 2 & Seg. 3 \\
\hline Max. Compounding & 0.9840 & 0.0743 & 0.0327 & 1.0461 & 0.0811 & 0.0305 & 0.6141 & 0.1023 & 0.0330 \\
\hline Avg. Compounding & 0.4093 & 0.0694 & 0.0324 & 0.4375 & 0.0685 & 0.0338 & 0.4422 & 0.1135 & 0.0320 \\
\hline Min. Compounding & 0.2126 & 0.0825 & 0.0398 & 0.2751 & 0.0759 & 0.0393 & 0.2886 & 0.1243 & 0.0319 \\
\hline Non. Compounding & 0.2285 & 0.0911 & 0.0447 & 0.1678 & 0.0859 & 0.0491 & 0.2794 & 0.1276 & 0.0416 \\
\hline
\end{tabular}

Table 1: Slopes of the four graphs in Figure 3 (unit reliability/\$)

\begin{tabular}{|c|c|c|c|c|c|c|c|c|c|c|c|c|c|}
\hline & \multicolumn{3}{|c|}{ Supplier nodes } & \multicolumn{4}{|c|}{ Plant nodes } & \multicolumn{5}{|c|}{ DC nodes } \\
\hline & & 1 & 2 & 3 & 4 & 5 & 6 & 7 & 8 & 9 & 10 & 11 & 12 \\
\hline$\exists$ & Capacity & 110 & 230 & 350 & 90 & 110 & 140 & 350 & 55 & 70 & 90 & 125 & 350 \\
\hline 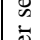 & Var. Cost & $\$ 4.81$ & $\$ 4.28$ & $\$ 4.01$ & $\$ 4.89$ & $\$ 4.75$ & $\$ 4.58$ & $\$ 4.01$ & $\$ 1.24$ & $\$ 1.21$ & $\$ 1.18$ & $\$ 1.14$ & $\$ 1.03$ \\
\hline 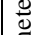 & Fix. Cost & $\$ 920.68$ & $\$ 1,050.49$ & $\$ 1,124.39$ & $\$ 2,752.56$ & $\$ 2,840.35$ & $\$ 2,945.86$ & $\$ 3,346.74$ & $\$ 1,823.74$ & $\$ 1,879.21$ & $\$ 1,937.01$ & $\$ 2,012.57$ & $\$ 2,249.38$ \\
\hline ్ㅠ & Ave. Cost & $\$ 13.18$ & $\$ 8.85$ & $\$ 7.22$ & $\$ 35.47$ & $\$ 30.57$ & $\$ 25.62$ & $\$ 13.57$ & $\$ 34.40$ & $\$ 28.06$ & $\$ 22.70$ & $\$ 17.24$ & $\$ 7.46$ \\
\hline 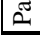 & Reliability & 2.83 & 1.63 & 1.02 & 6.33 & 6.07 & 5.75 & 4.60 & 9.89 & 9.64 & 9.38 & 9.04 & 8.01 \\
\hline$\sqrt{2}$ & Capacity & 100 & 220 & 350 & 80 & 105 & 135 & 350 & 50 & 65 & 85 & 120 & 350 \\
\hline$=$ & Var. Cost & $\$ 4.88$ & $\$ 4.31$ & $\$ 4.01$ & $\$ 4.97$ & $\$ 4.78$ & $\$ 4.61$ & $\$ 4.01$ & $\$ 1.25$ & $\$ 1.22$ & $\$ 1.19$ & $\$ 1.15$ & $\$ 1.03$ \\
\hline 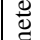 & Fix. Cost & $\$ 903.90$ & $\$ 1,042.67$ & $\$ 1,124.39$ & $\$ 2,701.03$ & $\$ 2,820.00$ & $\$ 2,929.95$ & $\$ 3,346.74$ & $\$ 1,801.82$ & $\$ 1,862.16$ & $\$ 1,923.86$ & $\$ 2,003.18$ & $\$ 2,249.38$ \\
\hline 클 & Ave. Cost & $\$ 13.92$ & $\$ 9.05$ & $\$ 7.22$ & $\$ 38.73$ & $\$ 32.98$ & $\$ 26.31$ & $\$ 13.57$ & $\$ 37.29$ & $\$ 29.87$ & $\$ 23.82$ & $\$ 17.84$ & $\$ 7.46$ \\
\hline ڤ & Reliability & 2.99 & 1.70 & 1.02 & 6.49 & 6.13 & 5.80 & 4.60 & 9.99 & 9.72 & 9.44 & 9.08 & 8.01 \\
\hline$\stackrel{m}{a}$ & Capacity & 95 & 210 & 335 & 75 & 100 & 130 & 335 & 50 & 60 & 75 & 110 & 335 \\
\hline 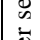 & Var. Cost & $\$ 4.92$ & $\$ 4.34$ & $\$ 4.04$ & $\$ 5.02$ & $\$ 4.81$ & $\$ 4.63$ & $\$ 4.04$ & $\$ 1.25$ & $\$ 1.23$ & $\$ 1.20$ & $\$ 1.16$ & $\$ 1.04$ \\
\hline$\stackrel{\mathscr{U}}{\square}$ & Fix. Cost & $\$ 894.87$ & $\$ 1,034.48$ & $\$ 1,116.68$ & $\$ 2,672.80$ & $\$ 2,798.66$ & $\$ 2,913.44$ & $\$ 3,327.58$ & $\$ 1,801.82$ & $\$ 1,843.75$ & $\$ 1,895.08$ & $\$ 1,983.16$ & $\$ 2,239.30$ \\
\hline ్ㅠㄴ & Ave. Cost & $\$ 14.34$ & $\$ 9.27$ & $\$ 7.37$ & $\$ 40.66$ & $\$ 32.80$ & $\$ 27.04$ & $\$ 13.97$ & $\$ 37.29$ & $\$ 31.96$ & $\$ 26.47$ & $\$ 19.19$ & $\$ 7.72$ \\
\hline$\approx$ & Reliability & 3.08 & 1.77 & 1.08 & 6.58 & 6.19 & 5.85 & 4.66 & 9.99 & 9.80 & 9.57 & 9.17 & 8.05 \\
\hline
\end{tabular}

Table A-1: Node parameters 


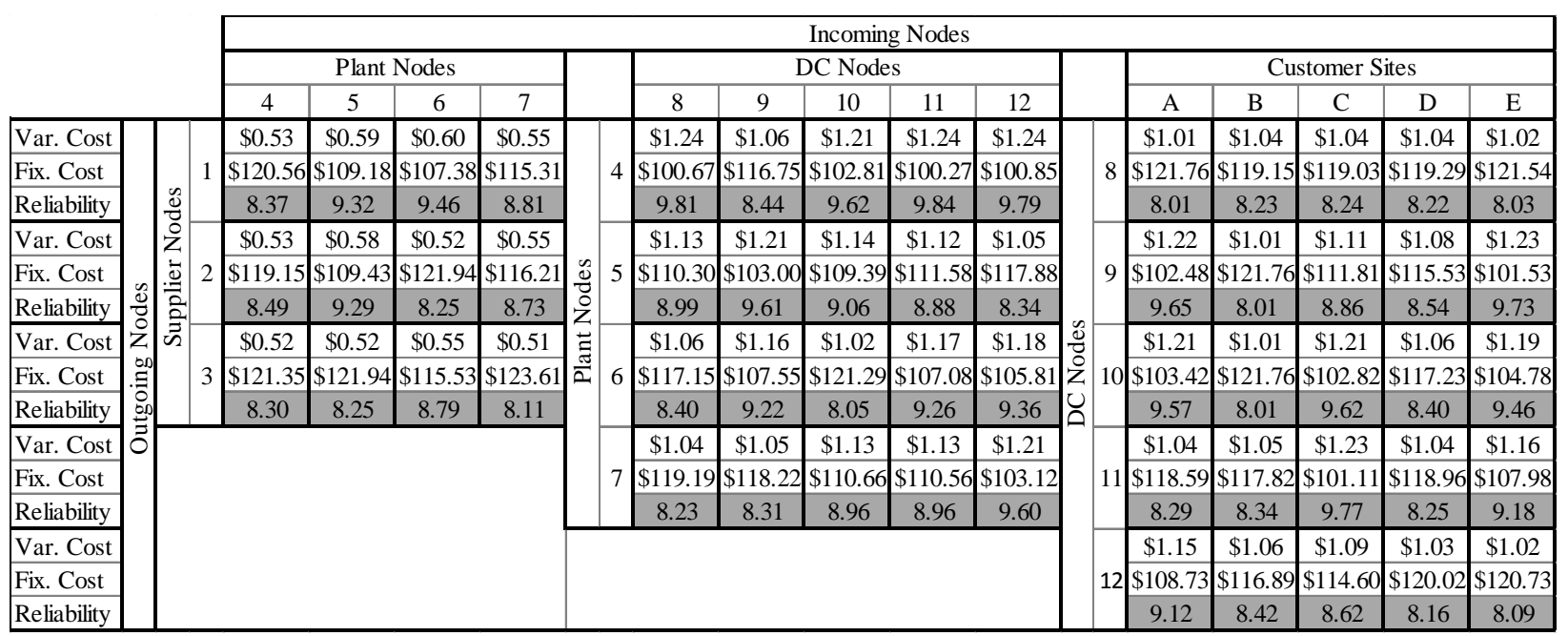

Table A-2: Arc parameters

Suppliers

- Quality

- Price Variability

- Flexibility

- On-time delivery

- Disruptions (e.g. financial, natural)
Distribution Centers

- Storage Quality

- Price Variability (includes tax/duty status, theft)

- Flexibility

- Service level (\% demand met)

- On time delivery (\% demand met on time)

- Disruptions (e.g. location risk)

Table A-3: Risk factors
Routes

- Flexibility (includes Capacity \& Mode Availability)

- Distance/Time

- Disruptions( e.g. Weather, Port, Piracy)
- Disruptions (e.g. labor availability, geopolitics) 


\section{University Library}

\section{- M M I N E R VA A gateway to Melbourne's research publications}

Minerva Access is the Institutional Repository of The University of Melbourne

Author/s:

Yildiz, H;Yoon, J;Talluri, S;Ho, W

Title:

Reliable Supply Chain Network Design

Date:

2016

Citation:

Yildiz, H., Yoon, J., Talluri, S. \& Ho, W. (2016). Reliable Supply Chain Network Design.

Decision Sciences, 47 (4), pp.661-698. https://doi.org/10.1111/deci.12160.

Persistent Link:

http://hdl.handle.net/11343/118645 